NBER WORKING PAPER SERIES

\title{
MAKING FRIENDS WITH YOUR NEIGHBORS? AGGLOMERATION AND TACIT COLLUSION IN THE LODGING INDUSTRY
}

\author{
Li Gan \\ Manuel A. Hernandez \\ Working Paper 16739 \\ http://www.nber.org/papers/w16739
NATIONAL BUREAU OF ECONOMIC RESEARCH
1050 Massachusetts Avenue
Cambridge, MA 02138
January 2011

We thank the valuable comments of Jimmy Chan, Brian Viard, Steven Wiggins, and seminar participants at Texas A\&M University, the International Industrial Organization Conference, and the European Economic Association annual meeting in 2010, and the American Economic Association annual meeting in 2011. The views expressed herein are those of the authors and do not necessarily reflect the views of the National Bureau of Economic Research.

NBER working papers are circulated for discussion and comment purposes. They have not been peerreviewed or been subject to the review by the NBER Board of Directors that accompanies official NBER publications.

(C) 2011 by Li Gan and Manuel A. Hernandez. All rights reserved. Short sections of text, not to exceed two paragraphs, may be quoted without explicit permission provided that full credit, including $\odot$ notice, is given to the source. 
Making friends with your neighbors? Agglomeration and tacit collusion in the lodging industry Li Gan and Manuel A. Hernandez NBER Working Paper No. 16739

January 2011

JEL No. C3,L13,L4

\begin{abstract}
Agglomeration is a location pattern frequently observed in service industries such as hotels. This paper empirically examines if agglomeration facilitates tacit collusion in the lodging industry using a quarterly dataset of hotels that operated in rural areas across Texas between 2003 and 2005. We jointly model a price and occupancy rate equation under a switching regression model to endogenously identify a collusive and non-collusive regime. The estimation results indicate that clustered hotels have a higher probability of being in the potential collusive regime than isolated properties in the same town. The identification of a collusive regime is also consistent with other factors considered to affect the sustainability of collusion like cluster size, seasonality and firm size, and the results are robust to alternative cluster definitions.
\end{abstract}

Li Gan

Department of Economics

Texas A\&M University

College Station, TX 77843-4228

and NBER

gan@econmail.tamu.edu

Manuel A. Hernandez

Markets, Trade, and Institution Division

IFPRI

m.a.hernandez@cgiar.org 


\section{Introduction}

Agglomeration is a location pattern frequently observed in service industries such as the lodging industry. A common assumption is that hotels locate close to one another to enjoy of agglomeration effects. Fischer and Harrington (1996), for example, indicate that in industries where products are heterogeneous and need personal inspection, agglomeration results in a heightened demand. By spatially concentrating, sellers reduce consumer's search costs and attract more customers as a group relative to what they could all attract individually. ${ }^{1}$ Helsley and Strange (1990) add that when firms are clustered, they help consumers to better evaluate their options. In the case of the lodging industry, Chung and Kalnins (2001) argue that agglomeration effects should be higher among hotels located in rural areas since most of them are overnight destinations in between days of travel, so a cluster of hotels may signal safety in an isolated area and/or indicate the availability of additional services. Other studies that have analyzed agglomeration effects in the hotel industry include Baum and Haveman (1997) and Kalnins and Chung (2004). However, not much has been said about the possibility that agglomeration may also facilitate the coordination of prices and quantities among hotels located next to each other. There is more anecdotal than empirical evidence on this matter. ${ }^{2}$

This paper seeks to empirically examine if agglomeration facilitates tacit collusion in the hotel industry. As revealed by Kalnins (2006), the exchange of price and occupancy information among hotels appears to be very common in the industry (e.g.

\footnotetext{
${ }^{1}$ See also Stahl (1982) and Wolinsky (1983).

${ }^{2}$ See Kalnins (2006) for some related examples.
} 
"call-arounds"). But agglomeration provides further opportunities for frequent firm interaction and can also facilitate the sustainability of a collusive agreement (if any) by increasing market transparency and reducing monitoring costs. ${ }^{3}$ More specifically, onsite inspection of rates and vacancy status is costless among clustered hotels, making it easier and faster to detect deviations from any potential agreement. For example, the number of cars in the parking lot of neighboring hotels can be easily counted or employees could regularly visit the lobbies of competitors to keep record of the volume of check-ins. We examine then whether agglomeration facilitates a collusive price and quantity setting. To our knowledge, this is the first empirical study to formally test this hypothesis.

The data used for the analysis is a quarterly data set of lodging properties that operated in Non Metropolitan Statistical Areas (Non MSA) across Texas between 2003 and 2005. Using the physical address of each lodging property in the data set, we are able to determine whether a hotel is clustered and the number of nearby competitors faced by each hotel within each town. Working with geographically isolated areas also enables us to avoid any market overlapping issues and correctly identify the total number of competitors within each market, as in Bresnahan and Reiss (1991) and Mazzeo (2002).

The novelty of our methodology is that we jointly model a price and occupancy rate equation using a switching regression model to endogenously identify a collusive and non-collusive regime. In the potential collusive regime, prices are expected to be higher and quantities (occupancy rates) to be lower, as predicted by general oligopoly models

\footnotetext{
${ }^{3}$ Our interviews with some hotel managers actually confirmed that hotels located close to one another exchange information on a regularly basis and adjust their rates accordingly.
} 
where firms interact repeatedly and find it profitable to cooperate under the threat of future punishment. ${ }^{4}$ Additionally, prices (and occupancy rates) are expected to exhibit a lower dispersion during successfully collusive periods. ${ }^{5}$ We then analyze if agglomeration increases the probability of being in the potential collusive regime.

Other studies that use some form of mixture modeling to endogenously identify collusive and non-collusive regimes include Porter (1983), Ellison (1994) and Knittel and Stango (2003). But these studies basically focus on the pricing behavior of firms. Porter (1983) estimates a switching regression model to classify prices into collusive and noncollusive regimes during the Joint Executive Committee cartel on railroads in the late 19th century; Ellison (1994) reexamines the experience of the railroad cartel using a Markov structure on the transitions between collusive and non-collusive periods; Knittel and Stango (2003) use a mixture density model to test whether nonbinding price ceilings may serve as focal points for tacit collusion in the credit card market. Further, we examine if our identification strategy is consistent with other factors thought to affect the sustainability of colluding, as in Knittel and Stango (2003). In particular, the probability of engaging into tacit collusion is allowed to vary with cluster size, seasonality and firm size.

The estimation results suggest that agglomeration facilitates tacit collusion. Clustered hotels show a higher probability of being in the suspected collusive regime than isolated properties in the same town. Further, our identification of a collusive regime

\footnotetext{
${ }^{4}$ See Tirole (1988).

${ }^{5}$ Recent studies suggesting that prices are more stable under collusion include Athey, Bagwell and Sanchirico (2004), Connor (2005) and Abrantes-Metz et al. (2006). For a general discussion on different behavioral patterns under collusion, refer to Harrington (2005).
} 
is also consistent with other factors considered to affect the sustainability of colluding, and the results are robust to alternative cluster definitions. Moreover, hotels without any competitors in a town (i.e. monopolists), whom behavior is similar to perfect collusion, also show a higher likelihood of being in the collusive regime.

The reminder of the paper is organized as follows. Section 2 further discusses how agglomeration can facilitate tacit collusion. Section 3 describes the data and certain empirical regularities of the lodging industry in rural areas across Texas. The empirical model is presented in Section 4. Section 5 reports the estimation results while Section 6 concludes.

\section{Agglomeration and tacit collusion}

This section briefly discusses the economics of tacit collusion and how agglomeration can facilitate the sustainability of a cooperative agreement among clustered firms. It is well established that tacit collusion can arise when firms interact repeatedly in the same market. Firms can achieve higher profits by tacitly agreeing to raise prices (and restrict quantity) above (below) the static Nash equilibrium level. Since cheating or deviating from the collusive agreement increases current profits, firms can only be deterred from deviating if they are penalized in the future. For example, if a firm deviates from the collusive or cooperative outcome at a particular time period, the other firms may respond by reverting to the non-cooperative outcome for a certain number of subsequent periods

(or forever). The collusive equilibrium condition or incentive compatibility (IC) 
constraint requires then that the present value of foregone future profits is greater than or equal to the current profits from deviating.

Consider $N$ firms each producing a differentiated product and competing in prices in an infinitely repeated game. All firms share the same unit cost of production. Let $p_{i}^{s}, i=1, \ldots, N$, be the price that maximizes firm $i$ 's profits $\left(\pi_{i}^{s}\right)$ in the static version of the game. If firms agree to cooperate by charging $p_{i}^{c}>p_{i}^{s}$ and obtaining profits $\pi_{i}^{c}$ in each period, then the IC constraint requires that,

$$
\sum_{t=1}^{T} \delta^{t}\left(\pi_{i}^{c}-\pi_{i}^{s}\right) \geq \pi_{i}^{d}-\pi_{i}^{c}
$$

where $\delta \in(0,1)$ is the discount factor equal across firms, $\pi_{i}^{d}$ are firm $i$ 's profits when deviating from the collusive agreement and choosing best-response price $p_{i}^{d}$ given all other firms' prices $p_{-i}^{c}$, and $T$ are the number of periods of reversion to the non-collusive outcome. Note that $\pi_{i}^{d}>\pi_{i}^{c}>\pi_{i}^{s}$. From the condition above, it follows that the collusive outcome is more likely to be an equilibrium the higher the discount factor $\delta$ or when $T$ is sufficiently high.

To see how agglomeration can facilitate collusion, assume that firms compete $f$ times in a given time period. The discount factor can then be defined as $\delta=\frac{1}{1+r / f}$, where $r$ is the interest rate in a given period (Cabral, 2000). Since clustered hotels are likely to interact more frequently than isolated properties and $\delta$ is increasing in the frequency of interaction among firms, it is clear that agglomeration can facilitate the 
sustainability of a collusive agreement. ${ }^{6}$ Intuitively, when firms interact more often, they can react more quickly if one of the firms deviates from the agreement, so collusion is easier to maintain. A similar idea applies if we consider that clustered hotels adjust their prices more frequently than isolated ones.

Additionally, agglomeration increases the transparency of the market and reduces monitoring costs. On-site inspections of both rates and vacancy status (parking lots) are costless among clustered hotels, making it easier and faster to detect deviations from any agreement. This, in turn, limits the potential profits from deviating or short term profits $\pi_{i}^{d}$, making collusion more easier to sustain among hotels in a cluster. ${ }^{7}$

\footnotetext{
${ }^{6}$ Alternatively, we can let $T=\infty$ and assume that firms only compete every $k$ periods, so the higher the frequency of interaction among firms the lower the value of $k$. It can be shown then that the critical threshold for the weight firms put on their future profits, i.e. the value of $\delta$ that makes equation (1) hold with equality, decreases with a lower $k$ (Ivaldi et al., 2003).

${ }^{7}$ It is worth to mention that the discussion above (and the posterior empirical analysis) on how agglomeration may facilitate tacit collusion takes geographic location as given. Friedman and Thisse (1991) have also shown that agglomeration is the only equilibrium outcome when collusion on price follows competition on location. Locating at the same point implies that firms' ability to punish one another for defection is maximized once the equilibrium locations are selected. The authors develop a spatial duopoly model in which firms simultaneously select their locations at the beginning of time (once and forever) and choose prices in each of a countable infinite succession of time periods. The critical assumption in their model is that firms have the ability, at the beginning of the game, to determine the set of price outcomes that are admissible in the subsequent repeated subgames. The authors also briefly discuss some model extensions. In particular, they argue that when location is chosen sequentially and collusion on prices takes place after entry, the second firm will locate at the same place as the first one, eliminating any first-mover advantage observed in the one-shot price game. But if location is chosen simultaneously and
} 
As noted, in the analysis we also control for factors, other than agglomeration, that can affect the sustainability of collusion. ${ }^{8}$ These other factors include number of competitors (cluster size), seasonality and firm size. We discuss later how these other variables can make a collusive agreement easier or more difficult to sustain. Next, we describe the data used for the study and some empirical regularities of the hotel industry in rural areas across Texas.

\section{Data}

The main data source of this paper is the Texas Hotel Performance Factbook, published every quarter by Source Strategies Inc.. This is a unique data set that contains information on room counts, average daily rates (ADR), and occupancy rates for all lodging properties in Texas exceeding 18,000 dollars per quarter in gross revenues. ${ }^{9}$ The data set also provides the hotel name and address, and indicates whether each property is

there are more than two firms, they sustain that firms' location will be affected by collusive pricing although it is not obvious that all firms will choose to locate together.

${ }^{8}$ For an extensive description of factors relevant for collusion see Ivaldi et al. (2003).

${ }^{9}$ See Table A.1 for a more detailed description of these variables. According to SSI, properties below 18,000 dollars per quarter result in approximately $1.5 \%$ of the total state revenues being excluded from this database. To our knowledge, this is one of the few datasets that provide detailed financial information of each lodging property in a whole state. Smith Travel Research (STR), a leading private research firm in the lodging industry, gets full financial reports from hotels/motels accounting for $80 \%$ of the market but only publishes aggregate results. They also maintain a Lodging Census Database which does not include financial information. 
affiliated to a "Top 50+" chain. ${ }^{10}$ Hotels are ordered by MSA/Non MSA, city/town and zip code. In this study, we focus on lodging properties that operated in Non MSA across the state between 2003 and 2005. This allows us to work with a comparable and geographically isolated set of oligopoly markets. Similar to Bresnahan and Reiss (1991) and Mazzeo (2002), by working with isolated markets we avoid any inter-market competition issues and correctly identify the number of competitors on each market. ${ }^{11}$ Overall, we have an unbalanced panel of 9,148 observations corresponding to 845 properties operating in 250 markets between the first quarter of 2003 and the fourth quarter of $2005 .{ }^{12}$

The data set was supplemented with quality ratings from the American Automobile Association's (AAA) online hotel directory (www.aaa-texas.com). In this directory, lodging properties are rated from one to five "diamonds", ranging from simple to luxurious. ${ }^{13}$ Following Mazzeo (2002), for those "Top 50+" chain-affiliated hotels not listed in the directory, we assigned the modal category of other chain-affiliated members that were in fact rated. Since AAA has minimum quality standards for inclusion of hotels

\footnotetext{
${ }^{10}$ The "Top 50+" chains are determined and tracked by Source Strategies Inc., and may vary across time.

${ }^{11}$ Bresnahan and Reiss (1991) study the relationship between the number of firms, market size and competition using a sample of 202 isolated local markets (county seats) in the western United States. Mazzeo (2002), in turn, analyzes the effect of market concentration and product differentiation on market outcomes using a cross section of 492 isolated motel markets located adjacent to small, rural exits along one of the 30 longest U.S. interstate highways.

${ }^{12}$ The unbalanced panel results from the fact that the information for certain hotels and markets is not fully reported by SSI across all periods, and due to a small number of entries/exits in some markets.

${ }^{13}$ Refer to Table A.2 for details of AAA Diamond rating. Hotels range from 1 to 4 diamonds in our sample.
} 
in their directory, we assigned the lowest category for independent properties and other minor chains not listed. These ratings allow us to control for quality in the estimations.

The data set was finally complemented with several control variables to account for different cost and demand conditions across markets. These variables include population, per capita personal income, number of gas stations at each location, value of rural land per acre, weekly wage on leisure and hospitality, distance to a MSA and regional dummies. ${ }^{14}$ Table A.3 describes the sources of information consulted to construct these variables.

\subsection{The Lodging Industry in Non MSA across Texas}

The total number of properties in Non MSA across the state increased at an annual growth rate of $2.9 \%$ between 1995 and 2005, totaling 790 hotels and motels by the end of $2005 .{ }^{15}$ The continuous upward trend in the supply of lodging units is reflected in the increase of room nights available, as shown in Figure 1. The number of rooms sold and, consequently, the occupancy rate did not follow a similar pattern. The latter showed a downward trend at the beginning of the present decade probably due to the recession of the economy and the 9/11 events, but recovered recently. The average occupancy rate in

\footnotetext{
${ }^{14}$ Distance to a MSA is measured as the mileage between the town and the nearest MSA.

${ }^{15}$ In the same time period, lodging properties in MSA report an annual growth rate of 4.7\%, totaling 3,194 hotels by the end 2005 .
} 
2005 was around $52 \%$, similar to the levels shown in the late 90 's. ${ }^{16}$ The total room revenues, on the contrary, showed a steady increase (explained in part by the increase in the ADR), reaching almost 200 million dollars in 2005. The ADR increased two dollars in real terms, or sixteen dollars in nominal terms, across the period.

As noted, we focus on the period 2003-2005. ${ }^{17}$ The whole list of locations in our sample, by region, is reported in Table A.4. Our unit of observation is a hotel-quarter pair. Table 1 presents the distribution of markets by number of operating firms at each point in time. ${ }^{18}$ It follows that our sample basically consists of small oligopolies. In four of every five markets observed, there are five or less hotels operating. More specifically, $37 \%$ of the markets are monopolies, $18 \%$ are duopolies and another $26 \%$ have between three and five competitors.

Table 2 indicates that more than $68 \%$ of the operating properties do not have more than 50 rooms and an additional $20 \%$ have between 51 and 75 rooms. The small capacity of these properties is consistent with the small size of the markets in our sample. In terms of the distribution of hotels by chain affiliation and quality type, Table 3 shows that

\footnotetext{
${ }^{16}$ As noted by Kalnins (2006), the nationwide occupancy rate of an average hotel is roughly $60 \%$ while the break-even occupancy (i.e. percentage of rooms that must be sold on average for a hotel to show positive pretax income) is estimated at around 53\% since 2000 .

${ }^{17}$ The second semester of 2005 may be an atypical period because of the sudden increase in the demand for hotel rooms after Katrina and Rita. However, according to a list of hotels/motels that participated in the Federal Emergency Management Agency's (FEMA) temporary housing program, provided by the same agency, most of the evacuees in Texas relocated in urban areas. In any case, we include time-period dummies in our estimates.

${ }^{18}$ Considering that we have data for 12 quarters, each market can be observed up to 12 times.
} 
independent hotels and small franchises remain quite common across rural areas. Two thirds of the properties are either independent or not affiliated to any of the "Top 50+" chains. Among the properties that represent a top chain, $26 \%$ are affiliated to Best Western, $13 \%$ to Holiday Inn Express or Holiday Inn, 12\% to Days Inn, 10\% to Comfort Inn or Comfort Suites and $10 \%$ to Super 8 .

There is a strong correlation between large franchises and quality type. Overall, $36 \%$ of the hotels in our sample are of high-quality, i.e. are rated with two or more "diamonds" according to AAA, and $88 \%$ of them represent a top chain. Since both chain affiliation and quality type are sources of product differentiation, we account for both of them in the estimations as well as for hotel size.

With respect to the geographical location of properties, relative to their nearby competitors, we find that $35 \%$ of them have at least one competitor in a radius of 0.2 miles. This fraction decreases to $24 \%$ if we reduce the ratio to 0.1 miles and increases to $52 \%$ if we extend the ratio to half a mile. Since the exact extent of a cluster is an empirical issue, we limit the cluster radius to 0.2 miles and compare our estimation results to those obtained under the other two alternative measures. ${ }^{19}$ These conservative measures are also in line with the idea that for agglomeration to facilitate the sustainability of a collusive agreement, hotels should be located sufficiently close to each other to interact (and adjust prices) frequently, increase market transparency and reduce monitoring costs, so any potential deviation can be easily and promptly detected.

\footnotetext{
${ }^{19}$ This empirical issue is similar to the problem that arises when establishing geographical boundaries to identify a firm's close competitors. Netz and Taylor (2002), for example, use market radii of half a mile, one mile and two miles in their study about gas stations' location patterns in Los Angeles. As indicated, we avoid any market definition issues because we work with rural areas which are generally isolated.
} 
In Table 4 we segment our sample of hotels into four groups: clustered hotels, isolated hotels with a cluster of hotels in town, monopolists (i.e. hotels without any competitors in town), and isolated hotels without any cluster in town. As can be seen, clustered hotels seem to be larger and of higher quality than the other groups of hotels. Monopolists, on the contrary, are much smaller and of lower quality while isolated hotels, with and without a cluster in town, are in between. In particular, among clustered hotels, $43 \%$ have more than 50 rooms and almost $50 \%$ are of high quality. Among isolated properties with a cluster of hotels in town, 33\% have more than 50 rooms and $41 \%$ are of high quality while among those without a cluster in town, the figures are $25 \%$ and $28 \%$, respectively. Finally, only $10 \%$ of the monopolists have more than 50 rooms and $91 \%$ are of low quality, probably due to the fact that monopolists are basically located in small markets.

For the present study, we are particularly interested in examining the price and occupancy rate behavior of clustered hotels relative to isolated ones in the same town. A preliminary look at the data reveals that clustered hotels seem to behave in a different manner than isolated properties. Figures 2 and 3 indicate that clustered hotels charge, on average, lower prices and have higher occupancy rates, regardless of the season of the year. Overall, the average daily rate of a room in clustered hotels is 52.8 dollars versus 57.6 dollars in isolated hotels with a cluster in town (see Table 5). The average occupancy rate among clustered properties is $51.3 \%$ and $49.8 \%$ among isolated properties. In terms of dispersion, clustered hotels exhibit a much lower dispersion in prices and a slightly lower dispersion in occupancy rates across the year. 
This initial look at the data provides mixed support regarding the hypothesis that agglomeration facilitates tacit collusion. If agglomeration increases the probability of colluding and if there are not any deviations from the collusive agreement, we would then expect a lower dispersion in prices and occupancy rates among clustered properties, relative to isolated ones, as observed. However, we would also expect clustered hotels to charge higher prices than isolated hotels and exhibit lower occupancy rates, but not the inverse. $^{20}$

Next, we formally examine whether agglomeration facilitates tacit collusion. We propose a switching regression model to endogenously classify prices and occupancy rates into collusive and non-collusive regimes, while controlling for several factors at the property and market level that may affect a firm's competitive behavior. We then examine whether agglomerated hotels exhibit a higher probability of colluding than isolated hotels in the same town.

\section{The Empirical Model}

\footnotetext{
${ }^{20}$ Alternatively, the differences in prices and occupancy rates between clustered and isolated hotels in a town could be explained in the context of the spatial competition literature, which considers a market power and a market share effect when clustering (e.g. Fujita and Thisse, 1996; Pinske and Slade, 1998; and Netz and Taylor, 2002). The market power effect predicts that, other things equal, firms will compete more intensively on prices when locating closer to each other (i.e. lower prices). But if the products between firms are differentiated enough, price competition may be weakened (Irmen and Thisse, 1998). The market share effect, in turn, predicts that firms will capture more customers when clustering (i.e. higher occupancy rates).
} 
This section develops a switching regime model to analyze if clustered hotels are more likely to engage in collusive behavior than isolated properties in the same town. We jointly model a price and occupancy rate equation under a mixture modeling to endogenously identify a collusive and non-collusive regime. We then analyze if agglomeration increases the probability of colluding. As in Knittel and Stango (2003), we also test whether our identification of the collusive regime is consistent with other factors thought to affect the sustainability of collusion. ${ }^{21}$

Let a firm's log-linear price $(p)$ and occupancy rate $(q)$ equations be given by,

$$
\begin{aligned}
& \ln p_{\text {imt }}=\delta_{1}^{s}+\delta_{2}^{s} \text { MktStructure }_{m t}+X_{\text {imt }} \gamma^{s}+\varepsilon_{\text {imt }}^{s} \text { and } \\
& \ln q_{\text {imt }}=\alpha_{1}^{s}+\alpha_{2}^{s} \text { MktStructure }_{m t}+X_{\text {imt }} \beta^{s}+u_{\text {imt }}^{s},
\end{aligned}
$$

where the subscript $i$ refers to a firm, $m$ to the market, and $t$ to the time period, and the superscript $s$ indicates one of two possible regimes, a collusive regime (C) and a noncollusive one (NC). The variable MktStructure $_{m t}$ measures the level concentration in the market through the Herfindahl-Hirshman Index (HHI), which is based on each firm's share of rooms sold, and the vector $X_{i m t}$ includes several property- and market-specific variables. The summary statistics of all variables used in the estimations are presented in Table 6.

The property-specific variables include dummy variables for the geographic location of hotels relative to their nearby competitors (i.e. clustered, isolated with a

\footnotetext{
${ }^{21}$ These authors point out that an omitted variable or misspecification of the functional form might lead to the spurious identification of two regimes, a collusive and a non-collusive one. They suggest then examining whether the probability of being in the identified collusive regime varies with factors thought to affect the sustainability of collusion.
} 
cluster of hotels in town, monopolist, isolated with no cluster in town), cluster size, a dummy variable if the hotel is of medium or large size (i.e. if the hotel has more than 50 rooms) and dummy variables for high-quality and affiliations to major chains in our sample. ${ }^{22}$ The market-specific variables include population, per capita personal income, number of gas stations, value of rural land per acre, wage on leisure and hospitality, distance to a MSA and regional dummies. These firm- and market-specific variables are intended to account for cost and demand factors that may affect a firm's competitive behavior, besides market concentration.

Further assume that the error terms in each regime $s, s=\{C, N C\}$, are bivariate normally distributed such that $\left(\varepsilon_{i m t}^{s}, u_{i m t}^{s}\right) \sim N_{2}\left(0,0, \sigma_{\varepsilon}^{s 2}, \sigma_{u}^{s 2}, \rho_{s}\right)$ where $\rho_{s}=\frac{\sigma_{\varepsilon u}^{s}}{\sigma_{\varepsilon}^{s} \sigma_{u}^{s}}$. Then, the log likelihood for the $j$ th firm-quarter period can be modeled as,

$$
\begin{aligned}
\ln l_{j}= & \ln \left(h \frac{1}{2 \pi \sigma_{\varepsilon}^{C} \sigma_{u}^{C} \sqrt{1-\rho_{C}^{2}}} \exp \left(\frac{-z_{j}^{C}}{2\left(1-\rho_{C}^{2}\right)}\right)\right. \\
& \left.+(1-h) \frac{1}{2 \pi \sigma_{\varepsilon}^{N C} \sigma_{u}^{N C} \sqrt{1-\rho_{N C}^{2}}} \exp \left(\frac{-z_{j}^{N C}}{2\left(1-\rho_{N C}^{2}\right)}\right)\right)
\end{aligned}
$$

where $z_{j}^{s}=\frac{\varepsilon_{j}^{s 2}}{\sigma_{\varepsilon}^{s 2}}+\frac{u_{j}^{s 2}}{\sigma_{u}^{s 2}}-\frac{2 \rho^{s} \varepsilon_{j}^{s} u_{j}^{s}}{\sigma_{\varepsilon}^{s} \sigma_{u}^{s}}$ and the mixing parameter $h, h \in[0,1]$, is defined as the probability that a firm will collude.

In the collusive regime, firms are expected to charge higher prices and exhibit lower occupancy rates (restrict output) than in the non-collusive regime. Additionally,

\footnotetext{
${ }^{22}$ Recall that a hotel is considered of high quality if it is rated with two or more "diamonds" according to AAA. The major chains include Best Western, Best Value, Comfort, Days, Econolodge, Holiday, Motel 6, Super 8 and Ramada.
} 
during successfully collusive periods we expect a lower dispersion in prices and occupancy rates. Consequently, identifying a potential collusive regime requires to test if $\delta_{1}^{C}>\delta_{1}^{N C}, \alpha_{1}^{C}<\alpha_{1}^{N C}, \sigma_{\varepsilon}^{C}<\alpha_{\varepsilon}^{N C}$, and $\sigma_{u}^{C}<\alpha_{u}^{N C}$.

The mixing parameter $h$ or probability of engaging into tacit collusion is modeled as a constant and as a function of the geographical location of a hotel relative to its nearby competitors. In the former case, $h=G(\kappa)$ where $\kappa$ is a constant and $G(\cdot)$ is approximated with a logistic CDF; in the latter case, $h_{j}=G\left(\kappa_{1}+\kappa_{2}\right.$ Clustered $_{j}+\kappa_{3}$ Monop $_{j}+\kappa_{4}$ Isolated_no_cluster $\left._{j}\right)$ where Clustered equals to one if the hotel has a nearby competitor in a radius of 0.2 miles, Monop equals to one if the hotel is the only one operating in the town, and Isolated_no_cluster equals to one if the hotel does not have a nearby competitor in a radius of 0.2 miles and there is not a cluster of hotels in town.$^{23}$ The first specification assumes that the probability of tacit collusion is constant across all hotels (and time periods) while the second specification allows us to evaluate whether the probability of being in a potential collusive regime varies with the relative location of the hotel within the town. Examining then if agglomeration facilitates collusion is equivalent to testing if $\kappa_{2}>0$.

Provided that our identification strategy of a collusive and non-collusive regime may be subject to an omitted variable or misspecification of the functional form, we also model $h$ as a function of other factors typically correlated with the sustainability of tacit collusion. These other factors include cluster size, seasonality and firm size. Tacit collusion is easier to maintain among fewer firms so the probability of being in a potential collusive regime should decrease with the number of firms in the cluster.

\footnotetext{
${ }^{23}$ The dummy variable for isolated properties with a cluster of hotels in town is the base variable.
} 
Similarly, collusion is less likely during high season periods because the gain from cheating during a peak-demand period is higher than the future punishment (Rotemberg and Saloner, 1986). ${ }^{24}$ Finally, the probability of colluding should also increase with firm size since deviations from any collusive agreement are typically more profitable for smaller than for larger firms. ${ }^{25}$

In the estimation of the price and occupancy rate equations specified in (2) and (3), some of the right-hand side variables are likely to be endogenous. In particular, the market-level $\mathrm{HHI}$ is presumably endogenous because there might be unobserved cost or demand characteristics in a market that not only influence prices (and occupancy rates) but also the underlying market structure. For example, markets with unobserved high costs are likely to have higher prices but these markets are also likely to exhibit fewer firm entries. We instrument the HHI with the HHI of the closest urban area to the town, obtained also from the Texas Hotel Performance Factbook. This instrument is valid under the assumption that market structure of the closest city, which is also affected by unobserved cost or demand characteristics in the area, is not influenced by prices (or occupancy rates) in a particular town.

Other potential endogenous variables include hotel size, quality type and location, although we treat them as predetermined. As indicated by Fernandez and Marin (1998),

\footnotetext{
${ }^{24}$ Alternatively, if both current demand and firms' expectations on future demand are allowed to change over time, it will be more difficult for firms to collude when demand is falling (i.e. during low seasons) since the foregone profits from inducing a price war are relatively low (Haltiwanger and Harrington, 1991). ${ }^{25}$ Smaller firms, however, may also have less to gain from undercutting their rivals because of their higher capacity constraints relative to larger firms. But hotels in rural areas (at least in Texas) seem to operate well below their capacity, as previously shown.
} 
the behavior of firms in the hotel industry can be represented as a sequential process. Initially, firms decide if they want to open an establishment in a particular location and simultaneously choose their capacity and quality. So these variables could be regarded as long-run decision variables. Firms compete then in prices (quantities) and take the establishments' capacity, quality and location as given. It is also important to note that in our working sample the number of entries and exits are very small, as well as the number of hotels that changed their affiliations (and possibly their capacity and/or quality level).

\section{Results}

We now turn to our estimation results. As noted, we instrument HHI with the HHI of the closest urban area to the town. Kleibergen and Paap's (2006) LM under-identification test and Wald weak-identification test indicate that the market-level HHI and HHI squared of the closest urban area are not weakly correlated with the market-level HHI of a particular town in our sample. ${ }^{26}$ Hansen's J statistic for overidentifying restrictions also indicates that with a five percent level of significance we cannot reject the null hypothesis that these instruments are valid instruments (i.e. uncorrelated with the error term in the price and occupancy rate equations). A semiparametric partially linear version of this firststage regression, where the $\mathrm{HHI}$ of the closest city is modeled nonparametrically and all other exogenous variables are modeled linearly, further increases the R-squared from

\footnotetext{
${ }^{26}$ Results are available upon request. The LM and Wald versions of the Kleibergen and Paap (2006) rk statistic are a generalization of the well-known Anderson LM test of canonical correlations and Cragg and Donald Wald test for weak identification to the case of non-i.i.d. errors.
} 
0.450 to 0.563 . So the HHI in equations (2) and (3) is replaced with the corresponding fitted values from the semiparametric partially linear regression. ${ }^{27}$

For comparison purposes, we first do not allow for the possibility of different regimes and separately estimate the price and occupancy rate equations by least squares. The results are reported in Table 7. Several of the coefficients of the explanatory variables have the expected signs and are statistically significant, particularly in the price equation. Regarding the property-specific characteristics, high-quality hotels charge, on average, $31.4 \%$ higher prices than low-quality ones, reflecting the higher costs associated with providing additional quality. These hotels report at the same time a $12.9 \%$ higher occupancy rate. Besides, medium and large hotels charge 5.6\% lower prices than small hotels and exhibit an $8.5 \%$ lower occupancy rate.

As in the preliminary analysis, clustered hotels seem to charge lower prices and exhibit higher occupancy rates than isolated hotels in the same town (base group in the regressions), although these effects are attenuated by the number of hotels in the cluster. Since we do not allow for two-regime periods, this result is probably only reflecting spatial competition and/or agglomeration effects. ${ }^{28}$ Monopolists and isolated hotels

\footnotetext{
${ }^{27}$ The estimation results presented in this section are very similar to those when using the lagged value of the market-level HHI as an alternative instrument for it (but we lose observations for one period).

${ }^{28}$ Recall that the spatial competition literature predicts a lower price among clustered (and homogeneous) hotels, relative to isolated properties, due to a price competition effect, and a higher occupancy rate due to a market share effect. The agglomeration literature predicts, in turn, a higher price and occupancy rate among clustered hotels because of a higher matching quality and matching probability effect. Testing for these effects is beyond the scope of the present study.
} 
without a cluster in town also face higher occupancy rates than isolated properties with a cluster in town, but do not report significant differences in prices.

With respect to the market-specific variables, market concentration has a negative effect on prices but it does not significantly affect occupancy rates. A one standard deviation increase in the HHI (0.28) results in a $3.1 \%$ decrease in prices. ${ }^{29}$ Prices are also positively correlated with the per capita income in the area. This is in line with the fact that wealthier locations usually have more businesses and places to visit, so we expect a higher number of visitors and higher prices. Hotels located in areas with higher wages and a higher value of land naturally charge higher prices because of the higher costs they face (but they also show lower occupancy rates). Additionally, the further away a hotel is from an urban area the higher the price it charges probably due to its higher market power in the vicinity of the area. A $10 \%$ increase in the distance to a MSA result in a $1.2 \%$ increase in prices. Curiously, population has a negative (although economically small) effect on both prices and occupancy rates. Finally, a higher number of gas stations in the area, which may approximate potential demand for hotel rooms, have a positive effect on occupancy rates but a negative impact on prices. ${ }^{30}$

We now turn to the MLE results of the switching regression model which endogenously classifies prices and occupancy rates into two regimes. As noted above, we jointly model a price and occupancy rate equation under each regime. The results are

\footnotetext{
${ }^{29}$ This result might seem counterintuitive but recall that for several oligopolistic competition models prices fall with market concentration (Sutton, 1991).

${ }^{30}$ Gas stations exist to serve both residents of and travelers passing through and visiting a market. As indicated by Chung and Kalnins (2001), a higher number of gas stations in a market might also indicate that the area is well located as an intermediate point from one major destination to another.
} 
presented in Table 8. Regime 1 is the potential collusive regime provided that hotels charge significantly higher prices than in regime 2 and face lower occupancy rates. ${ }^{31}$ Prices and occupancy rates also show a lower dispersion during regime 1. In Model 1, the mixing parameter $h$ or probability of being in the suspected collusive regime is modeled as a constant while in Model 2 we allow this probability to vary depending on the relative location of the hotel within the town. In Model 3, we control for additional factors considered to affect the sustainability of tacit collusion.

As can be seen, all three specifications provide very similar results regarding the impact of firm- and market-specific variables on prices and occupancy rates. It follows that when allowing for two regimes, the magnitude and direction of the effect of several of the control variables are not necessarily similar to those obtained under the leastsquares approach and may vary by regime. ${ }^{32}$ For example, quality type has a higher positive impact during the suspected collusive regime. In Model 3, during the collusive period, high-quality hotels charge almost $48 \%$ higher prices than low-quality hotels and report a $13.4 \%$ higher occupancy rate; during the non-collusive period, the price and occupancy rate difference between high- and low-quality hotels is not significantly different. Medium and large lodging properties exhibit lower occupancy rates than small

\footnotetext{
${ }^{31}$ This follows from the magnitude and significance of the constant terms under each regime. We also infer from these results that the switching regression model is not just distinguishing between high- and lowdemand seasons since in high seasons we expect both a high price and occupancy rate. Later we show that there is a lower probability of being in regime 1 (high prices, lower occupancy rates) during high seasons, i.e. second and third quarter of the year.

${ }^{32}$ Note that we allow for different coefficients of the control variables under each regime in order to have a more flexible model.
} 
properties during both regimes (as in the least-squares approach), but they only charge lower prices during non-collusive periods; during potential collusive periods they charge around 3\% higher prices. Further, clustered hotels only seem to charge lower prices than isolated properties with a cluster in town during the non-collusive regime $(60.6 \%$ lower prices) while during the suspected collusive regime they charge higher prices $(11.4 \%$ higher prices) as well as monopolists and isolated properties without a cluster in town. In terms of occupancy rates, the results are less clear since clustered hotels report a higher occupancy rate during regime 1 and a lower occupancy rate during regime 2. Monopolists and isolated hotels without a cluster in town only report higher occupancy rates (as in the least-squares approach) during regime 2 . Besides, market concentration only has a negative effect on prices during the non-collusive regime (as well as a negative effect on occupancy rates); during the collusive regime, a one standard deviation increase in the HHI results in a $5.5 \%$ increase in prices. Other market controls that show significant opposite effects across regimes include per capita income, wages, proximity to a MSA and number of gas stations. ${ }^{33}$

Moving to the likelihood of being in regime 1, the potential collusive regime, in Model 1 we observe that the sample-wide probability is equal to $68.3 \%{ }^{34}$ When we allow in Model 2 for the probability to vary with the geographical location of hotels, relative to their local competitors, we find that clustered hotels have a higher probability

\footnotetext{
${ }^{33}$ Although examining the impact of different control variables on hotels' prices and occupancy rates is not the main objective of the present study, these results reflect the importance of allowing for different regimes if we want to analyze the marginal effects of firm- and market-specific characteristics on hotels' competitive behavior.

${ }^{34}$ In the regression, we estimate $\kappa=0.769$ and $h=\exp (0.769) /(1+\exp (0.769))=0.683$.
} 
of engaging into tacit collusion than isolated properties with a cluster in town (base group). In particular, having a competitor in a radius of 0.2 miles increases the probability by more than twelve percentage points, from 64.8 to $76.9 \%$. Similarly, monopolists, whom behavior should be close to perfect collusion, also show a higher likelihood of being in the potential collusive regime. The probability increases in this case by almost ten percentage points (to 74.7\%). Isolated hotels without a cluster in town, on the contrary, show a lower probability of being in regime 1 than isolated properties with a cluster in town. The probability decreases by six percentage points (to $58.8 \%$ ).

If we further control for cluster size, seasonality and firm size, we still find that clustered hotels and monopolists have a higher probability of being in the potential collusive regime while isolated properties without a cluster have a lower probability (Model 3). Hotels with at least one competitor in a radius of 0.2 miles exhibit a $72.6 \%$ probability of being in the collusive regime, other things constant, while isolated hotels with a cluster in town only show a $60.8 \%$ probability. Monopolists show, in turn, a $72.8 \%$ probability of being in regime 1 while isolated hotels without a cluster in town show a $55.1 \%$ probability. The direction of the coefficients of the other control variables is also consistent with the discussion of factors, other than agglomeration, considered to affect the sustainability of collusion. The likelihood of tacit collusion decreases with the number of hotels in the cluster provided that it is easier to collude among fewer firms; decreases during high seasons given that collusion is more difficult to maintain during high-demand periods (Rotemberg and Saloner, 1986); and increases with hotel size provided that deviations from a collusive agreement are less profitable for large firms. Figure 4 illustrates the effects of these other variables by plotting the estimated 
probability of colluding, conditional on being clustered, as a function of the number of hotels in the cluster and by seasonality and hotel size.

In sum, the results suggest that agglomeration facilitates tacit collusion. Clustered hotels show a higher probability of being in the potential collusive regime than isolated hotels in the same town. Our identification of the collusive regime is also consistent with other factors thought to affect the sustainability of colluding. Furthermore, monopolists, whom behavior is similar to perfect collusion, show as well a higher likelihood of being in the collusive regime while isolated properties without a cluster in town exhibit a lower probability. Monopolists are naturally expected to just follow one regime, equivalent to a perfectly collusive one, regardless of seasonal fluctuations in demand or any other factors. Based on the estimated probabilities of being in regime 1 (derived from Models 2 and 3 for each hotel in our sample), we find that monopolistic firms are in fact the only group of hotels that are always predicted to follow the potential collusive regime.

As a robustness check, we examine whether these findings persist under alternative cluster definitions. We consider a cluster radius of 0.1 miles and a cluster radius of 0.5 miles. The results are presented in Table 9 where regime 1 is the potential collusive regime with higher prices, lower occupancy rates and a lower dispersion in both market outcomes (relative to regime 2). Note that the estimated coefficients of the control variables under the two alternative cluster definitions are very similar to the ones obtained with a cluster radius of 0.2 miles (Model 3 in Table 8). If we either restrict the cluster radius to 0.1 miles or expand the cluster radius to 0.5 miles, we still observe that clustered properties have a higher probability of engaging into tacit collusion than isolated properties with a cluster in town. In the case of a cluster radius of 0.1 miles, 
having a nearby competitor increases the probability by about 17 percentage points, holding all else constant, while in the case of a cluster radius of 0.5 miles, the probability increases by about 26 percentage points. Monopolists again have a higher probability of being in the collusive regime while isolated properties without a cluster in town have a lower, but not significant, probability of being in regime 1 . The likelihood of being in the identified collusive regime is also negatively related to cluster size and high-demand seasons and positively related to firm size. For comparison purposes, in Figure 5 we plot the probability of colluding, conditional on being clustered, as a function of cluster size for the different cluster definitions.

\section{Conclusions}

This paper has empirically examined if agglomeration facilitates tacit collusion in the lodging industry using a quarterly dataset of hotels that operated in rural areas across Texas between 2003 and 2005. Unlike previous studies that use some form of mixture modeling and focus on price behavior, we jointly model a price and occupancy rate equation under a switching regression model to endogenously identify a collusive and non-collusive regime. In the potential collusive regime, hotels are expected to charge higher prices and exhibit lower occupancy rates than in the non-collusive regime, and both prices and occupancy rates are expected to show a lower dispersion. We then analyze if agglomeration increases the probability of being in the collusive regime.

The results indicate that clustered hotels have a higher probability of being in the potential collusive regime than isolated hotels with a cluster in town. In particular, hotels 
with a nearby competitor in a radius of 0.2 miles are about twelve percentage points more likely of being in the collusive regime than isolated properties in the same town. Our identification of a collusive regime is also consistent with other factors considered to affect the sustainability of collusion like cluster size, seasonality and firm size, and the results are robust to alternative cluster definitions. Further, monopolists, whom behavior should be similar to perfect collusion, also show a higher likelihood of being in the collusive regime.

These findings support the hypothesis that agglomeration may facilitate tacit collusion by providing opportunities for frequent interaction among clustered hotels, increasing market transparency, and reducing monitoring costs if there is any collusive agreement. The inclusion of other variables thought to affect the sustainability of collusion cannot completely rule out any potential misspecification error in our identification strategy but reduces the possibility of alternative explanations for the results obtained. The nature of our dataset (i.e. quarterly data) prevents us from considering alternative identification strategies; for example, allowing for reversion periods during the collusive regime. Similarly, we take long-run decision variables like capacity, quality and geographic location as given due to the small number of entries/exits and change of affiliations in our sample. Future research should incorporate dynamic aspects into the analysis of agglomeration and tacit collusion. 


\section{References}

Abrantes-Metz, Rosa M., Luke M. Froeb, John F. Geweke, and Christopher T. Taylor, “A variance screen for collusion," International Journal of Industrial Organization 24:3 (2006), 467-486.

Athey, Susan, Kyle Bagwell, and Chris Sanchirico, "Collusion and Price Rigidity," Review of Economic Studies 71:2 (2004), 317-349.

Baum, Joel A. C., and Heather A. Haveman, "Love Thy Neighbor? Differentiation and Agglomeration in the Manhattan Hotel Industry, 1898-1990," Administrative Science Quarterly 42:2 (1997), 304-338.

Bresnahan, Timothy F., and Peter C. Reiss, "Entry and Competition in Concentrated Markets," Journal of Political Economy 99:5 (1991), 977-1009.

Cabral, Luis, "Introduction to Industrial Organization," The MIT Press (2000).

Connor, John M., "Collusion and price dispersion," Applied Economics Letters 12:6 (2005), 335-338.

Chung, Wilbur, and Arturs Kalnins, "Agglomeration Effects and Performance: A Test of the Texas Lodging Industry," Strategic Management Journal 22:10 (2001), 969-988. 
Ellison, Glenn, "Theories of Cartel Stability and the Joint Executive Committee," RAND Journal of Economics 25:1 (1994), 37-57.

Fernandez, Nerea and Pedro L. Marin, "Market Power and Multimarket Contact: Some Evidence from the Spanish Hotel Industry," Journal of Industrial Economics 46:3 (1998), 301-315.

Fischer, Jeffrey H., and Joseph E. Harrington Jr., "Product Variety and Firm Agglomeration," RAND Journal of Economics 27:2 (1996), 281-309.

Friedman, James W., and Jacques-Francois Thisse, "Infinite Horizon Spatial Duopoly with Collusive Pricing and Noncollusive Location Choice," CORE Discussion Paper No. 9104, Universite Catholique de Louvain (1991).

Fujita, Masahisa, and Jacques-Francois Thisse, "Economics of Agglomeration," Journal of the Japanese and International Economies 10:4 (1996), 339-378.

, Economics of Agglomeration: Cities, Industrial Location, and Regional Growth, Cambridge University Press (2002).

Haltiwanger, John, and Joseph E. Harrington Jr., "The Impact of Cyclical Demand Movements on Collusive Behavior," RAND Journal of Economics 22:1 (1991), 89-106. 
Harrington, Joseph E., "Detecting Cartels," Working paper John Hopkins University (2005).

Helsley, Robert W., and William C. Strange, "Matching and Agglomeration Economies in a System of Cities," Regional Science and Urban Economics 20:2 (1990), 189-212.

Irmen, Andreas, and Jacques-Francois Thisse, "Competition in Multi-characteristics Spaces: Hotelling was Almost Right,” Journal of Economic Theory 78:1 (1998), 76-102.

Ivaldi, Marc, Bruno Jullien, Patrick Rey, Paul Seabright, and Jean Tirole, "The Economics of Tacit Collusion," Final Report for DG Competition, European Commission (2003).

Kalnins, Arturs, "The U.S. Lodging Industry," Journal of Economic Perspectives 20:4 (2006), 203-218.

Kalnins, Arturs, and Wilbur Chung, "Resource-Seeking Agglomeration: A Study of Market Entry in the Lodging Industry," Strategic Management Journal 25:7 (2004), 689699.

Kleibergen, Frank, and Richard Paap, "Generalized reduced rank tests using the singular value decomposition," Journal of Econometrics 133:1 (2006), 97-126. 
Knittel, Christopher R., and Victor Stango, "Price Ceilings as Focal Points for Tacit Collusion: Evidence from Credit Cards," American Economic Review 93:5 (2003), 17031729.

Mazzeo, Michael, "Competitive Outcomes in Product-Differentiated Oligopoly," Review of Economics and Statistics 84:4 (2002), 716-728.

Netz, Janet S., and Beck A. Taylor, "Maximum or Minimum Differentiation? Location Patterns of Retail Outlets," Review of Economics and Statistics 84:1 (2002), 162-175.

Pinkse, Joris, and Margaret E. Slade, "Contracting in Space: An application of spatial statistics to discrete choice models," Journal of Econometrics 85:1 (1998), 125-154.

Porter, Robert H., “A Study of Cartel Stability: The Joint Executive Committee, 18801886," Bell Journal of Economics 14:2 (1983), 301-314.

Rotemberg, Julio J., and Garth Saloner, "A Supergame-Theoretic Model of Price Wars during Booms," American Economic Review 76:3 (1986), 390-407.

Stahl, Konrad, "Differentiated Products, Consumer Search, and Locational Oligopoly," Journal of Industrial Economics 31:1/2 (1982), 97-113. 
Sutton, John, Sunk Costs and Market Structure, The MIT Press (1991).

Tirole, Jean, The Theory of Industrial Organization, The MIT Press (1988).

Wolinsky, Asher, "Retail Trade Concentration due to Consumers' Imperfect Information,” Bell Journal of Economics 14:1 (1983), 275-282. 
Table 1: Distribution of markets by number of hotels

\begin{tabular}{lrr}
\hline $\begin{array}{c}\text { \# hotels in } \\
\text { market }\end{array}$ & \# markets & $\%$ \\
\hline 1 & 1,027 & 37.1 \\
2 & 508 & 18.3 \\
3 & 380 & 13.7 \\
4 & 133 & 4.8 \\
5 & 204 & 7.4 \\
6 & 129 & 4.7 \\
7 & 79 & 2.9 \\
8 & 55 & 2.0 \\
9 & 68 & 2.5 \\
10 & 56 & 2.0 \\
More than 10 & 132 & 4.8 \\
& & \\
Total & 2,771 & 100.0 \\
\hline
\end{tabular}




\section{Table 2: Distribution of hotels by size}

\begin{tabular}{lrr}
\hline \multicolumn{1}{c}{ Size } & \# hotels & \multicolumn{1}{c}{$\%$} \\
\hline Less than 25 rooms & 268 & 30.8 \\
26 - 50 rooms & 326 & 37.5 \\
$51-75$ rooms & 171 & 19.7 \\
76 - 100 rooms & 62 & 7.1 \\
More than 100 rooms & 43 & 4.9 \\
& & \\
Total & 870 & 100.0 \\
\hline
\end{tabular}

Note: There are more than 845 observations because 23 of the lodging properties changed their affiliation during the sample period. 
Table 3: Distribution of hotels by chain affiliation and quality type

\begin{tabular}{lrrrr}
\cline { 2 - 4 } \multicolumn{1}{c}{ Chain affiliation } & \multicolumn{3}{c}{ Quality rating } & \% total \\
\cline { 1 - 3 } Best Western & 0 & 78 & 78 & 9.0 \\
Holiday & 0 & 39 & 39 & 4.5 \\
Days & 1 & 35 & 36 & 4.1 \\
Comfort & 0 & 30 & 30 & 3.4 \\
Super 8 & 1 & 29 & 30 & 3.4 \\
Econolodge & 0 & 16 & 16 & 1.8 \\
Ramada & 1 & 12 & 13 & 1.5 \\
Motel 6 & 12 & 0 & 12 & 1.4 \\
Best Value & 1 & 10 & 11 & 1.3 \\
Other chains & 8 & 29 & 37 & 4.3 \\
& & & & \\
Total "Top 50+" chains & 24 & 278 & 302 & 34.7 \\
Others & 530 & 38 & 568 & 65.3 \\
\hline Total & 554 & 316 & 870 & 100.0 \\
\% total & 63.7 & 36.3 & 100.0 & \\
\hline
\end{tabular}

Note: There are more than 845 observations because 23 of the lodging properties changed their affiliation during the sample period. Low and high quality correspond to one and two or more "diamonds", respectively, under AAA's rating. Holiday includes Holiday Inn and Holiday Inn Express while Comfort includes Comfort Inn and Comfort Suites. 
Table 4: Distribution of hotels by relative location, size and quality type

\begin{tabular}{|c|c|c|c|c|c|c|c|c|c|c|}
\hline & \multicolumn{2}{|c|}{ Clustered } & \multicolumn{2}{|c|}{$\begin{array}{l}\text { Isolated, cluster } \\
\text { in town }\end{array}$} & \multicolumn{2}{|c|}{ Monopolist } & \multicolumn{2}{|c|}{$\begin{array}{l}\text { Isolated, no } \\
\text { cluster in town }\end{array}$} & \multicolumn{2}{|c|}{ Total } \\
\hline & $\#$ & $\%$ & $\#$ & $\%$ & $\#$ & $\%$ & \# & $\%$ & $\#$ & $\%$ \\
\hline \multicolumn{11}{|l|}{ By size } \\
\hline Up to 25 rooms & 57 & 18.8 & 62 & 27.9 & 56.0 & 55.5 & 93.0 & 38.3 & 268 & 30.8 \\
\hline $26-50$ rooms & 116 & 38.2 & 86 & 38.7 & 35.0 & 34.7 & 89.0 & 36.6 & 326 & 37.5 \\
\hline $51-75$ rooms & 74 & 24.3 & 46 & 20.7 & 8.0 & 7.9 & 43.0 & 17.7 & 171 & 19.7 \\
\hline $76-100$ rooms & 34 & 11.2 & 13 & 5.9 & 1.0 & 1.0 & 14.0 & 5.8 & 62 & 7.1 \\
\hline More than 100 rooms & 23 & 7.6 & 15 & 6.8 & 1.0 & 1.0 & 4.0 & 1.7 & 43 & 4.9 \\
\hline \multicolumn{11}{|l|}{ By quality type } \\
\hline Low & 157 & 51.6 & 132 & 59.5 & 91.0 & 90.1 & 174.0 & 71.6 & 554 & 63.7 \\
\hline High & 147 & 48.4 & 90 & 40.5 & 10.0 & 9.9 & 69.0 & 28.4 & 316 & 36.3 \\
\hline Total & 304 & 100.0 & 222 & 100.0 & 101 & 100.0 & 243 & 100.0 & 870 & 100.0 \\
\hline$\%$ total & 34.9 & & 25.5 & & 11.6 & & 27.9 & & 100.0 & \\
\hline
\end{tabular}

Note: There are more than 845 observations because 23 of the lodging properties changed their affiliation during the sample period. A hotel is considered clustered if it has a competitor in a radius of 0.2 miles. Low and high quality correspond to one and two or more "diamonds", respectively, under AAA's rating. 
Table 5: ADR and occupancy rate by relative location

ADR Occupancy rate

\section{Mean}

Clustered

52.8

51.3

Isolated, cluster in town

57.6

49.8

t-test

0.00

0.00

Total sample

55.2

49.5

\section{Standard deviation}

Clustered

24.5

15.1

Isolated, cluster in town

34.2

15.8

sd-test

0.00

0.01

Total sample

33.8

15.6

Note: A hotel is considered clustered if it has a competitor in a radius of 0.2 miles. Mean comparison test is based on two sample t-test with unequal variances using Welch's formula for degrees of freedom; $\operatorname{Prob}(|\mathrm{T}|>|\mathrm{t}|)$ reported. Equality of variance test based on Levene's robust test; $\operatorname{Pr}>$ F reported. 
Table 6: Summary statistics for variables used in the analysis

\begin{tabular}{|c|c|c|c|c|}
\hline & & & & \\
\hline & Mean & St. dev. & Min & Max \\
\hline ADR (US\$) & 55.2 & 33.8 & 17.5 & 524.2 \\
\hline Occupancy rate & 0.50 & 0.16 & 0.02 & 0.98 \\
\hline \multicolumn{5}{|l|}{ Firm variables } \\
\hline Clustered & 0.35 & 0.48 & 0.00 & 1.00 \\
\hline Isolated, cluster in town & 0.26 & 0.44 & 0.00 & 1.00 \\
\hline Monopolist & 0.11 & 0.32 & 0.00 & 1.00 \\
\hline Isolated, no cluster in town & 0.27 & 0.44 & 0.00 & 1.00 \\
\hline Number of nearby hotels & 1.76 & 1.40 & 1.00 & 9.00 \\
\hline Clustered (0.1 miles) & 0.25 & 0.43 & 0.00 & 1.00 \\
\hline Number of nearby hotels ( 0.1 miles) & 1.38 & 0.79 & 1.00 & 6.00 \\
\hline Clustered ( 0.5 miles $)$ & 0.53 & 0.50 & 0.00 & 1.00 \\
\hline Number of nearby hotels ( 0.5 miles) & 2.75 & 2.68 & 1.00 & 14.00 \\
\hline Medium or large hotel & 0.32 & 0.47 & 0.00 & 1.00 \\
\hline High quality & 0.37 & 0.48 & 0.00 & 1.00 \\
\hline Best Western & 0.09 & 0.29 & 0.00 & 1.00 \\
\hline Best Value & 0.01 & 0.11 & 0.00 & 1.00 \\
\hline Comfort & 0.03 & 0.18 & 0.00 & 1.00 \\
\hline Days & 0.04 & 0.20 & 0.00 & 1.00 \\
\hline Econolodge & 0.02 & 0.13 & 0.00 & 1.00 \\
\hline Holiday & 0.05 & 0.21 & 0.00 & 1.00 \\
\hline Motel 6 & 0.02 & 0.12 & 0.00 & 1.00 \\
\hline Super 8 & 0.04 & 0.19 & 0.00 & 1.00 \\
\hline Ramada & 0.02 & 0.12 & 0.00 & 1.00 \\
\hline \multicolumn{5}{|l|}{ Market variables } \\
\hline HHI & 0.34 & 0.28 & 0.06 & 1.00 \\
\hline Population & 26,960 & 18,617 & 370 & 82,055 \\
\hline Per capita personal income (US\$) & 23,839 & 4,590 & 11,013 & 55,301 \\
\hline Gas stations & 12 & 9 & 0 & 40 \\
\hline Value of land per acre (US\$) & 1,689 & 1,243 & 150 & 5,785 \\
\hline Weekly wage (US\$) & 208 & 42 & 93 & 480 \\
\hline Distance to a MSA (miles) & 69.2 & 33.4 & 22.4 & 252.0 \\
\hline Central Texas & 0.14 & 0.35 & 0.00 & 1.00 \\
\hline Gulf Coast & 0.05 & 0.21 & 0.00 & 1.00 \\
\hline High Plains & 0.10 & 0.30 & 0.00 & 1.00 \\
\hline Metroplex & 0.07 & 0.25 & 0.00 & 1.00 \\
\hline Northwest Texas & 0.08 & 0.26 & 0.00 & 1.00 \\
\hline South Texas & 0.23 & 0.42 & 0.00 & 1.00 \\
\hline Southeast Texas & 0.07 & 0.26 & 0.00 & 1.00 \\
\hline Upper East Texas & 0.12 & 0.33 & 0.00 & 1.00 \\
\hline Upper Rio Grande & 0.05 & 0.22 & 0.00 & 1.00 \\
\hline West Texas & 0.08 & 0.27 & 0.00 & 1.00 \\
\hline \# observations & & & & 9,148 \\
\hline
\end{tabular}


Table 7: Least squares regressions of price (ADR) and occupancy rate

\begin{tabular}{lrrrr} 
& \multicolumn{2}{c}{ Log ADR } & \multicolumn{2}{c}{ Log Occ } \\
\cline { 2 - 5 } & Coeff. & Std. err. & Coeff. & Std. err. \\
\hline Constant & -0.787 & 0.512 & 0.108 & 0.293 \\
Clustered & -0.152 & 0.030 & 0.066 & 0.018 \\
Monopolist & -0.035 & 0.029 & 0.091 & 0.021 \\
Isolated, no cluster in town & -0.016 & 0.021 & 0.048 & 0.015 \\
Log nearby hotels & 0.088 & 0.028 & -0.041 & 0.015 \\
Medium or large hotel & -0.056 & 0.011 & -0.085 & 0.010 \\
High quality & 0.314 & 0.019 & 0.129 & 0.014 \\
Best Western & 0.041 & 0.018 & 0.208 & 0.014 \\
Best Value & -0.427 & 0.032 & -0.102 & 0.032 \\
Comfort & 0.176 & 0.019 & 0.219 & 0.018 \\
Days & -0.114 & 0.019 & 0.070 & 0.017 \\
Econolodge & -0.230 & 0.021 & -0.128 & 0.024 \\
Holiday & 0.260 & 0.019 & 0.324 & 0.015 \\
Motel 6 & -0.082 & 0.022 & 0.380 & 0.015 \\
Super 8 & -0.154 & 0.020 & 0.083 & 0.018 \\
Ramada & -0.205 & 0.025 & 0.055 & 0.026 \\
HHI & -0.136 & 0.060 & -0.088 & 0.047 \\
Log population & -0.036 & 0.013 & -0.031 & 0.009 \\
Log per capita income & 0.241 & 0.043 & -0.020 & 0.026 \\
Gas stations & -0.011 & 0.002 & 0.005 & 0.001 \\
Log value of land & 0.135 & 0.015 & -0.014 & 0.010 \\
Log wage & 0.198 & 0.047 & -0.085 & 0.032 \\
Log distance to MSA & 0.123 & 0.017 & -0.014 & 0.012 \\
Central Texas & 0.169 & 0.034 & -0.073 & 0.026 \\
High Plains & 0.003 & 0.038 & -0.047 & 0.031 \\
Metroplex & 0.241 & 0.042 & -0.035 & 0.029 \\
Northwest Texas & -0.026 & 0.036 & -0.033 & 0.028 \\
South Texas & 0.275 & 0.034 & 0.030 & 0.026 \\
Southeast Texas & 0.167 & 0.039 & -0.005 & 0.029 \\
Upper East Texas & 0.253 & 0.032 & -0.028 & 0.026 \\
Upper Rio Grande & 0.381 & 0.056 & 0.067 & 0.041 \\
West Texas & 0.128 & 0.041 & 0.003 & 0.031 \\
\hline \# observations & & 9,148 & & 9,148 \\
R-squared & 0.272 & & 0.204 \\
\hline Not White robst & & &
\end{tabular}

Note: White robust standard errors reported, clustered on area-time period.

All models include time-period dummies. 
Table 8: Switching regression model of price (ADR) and occupancy rate

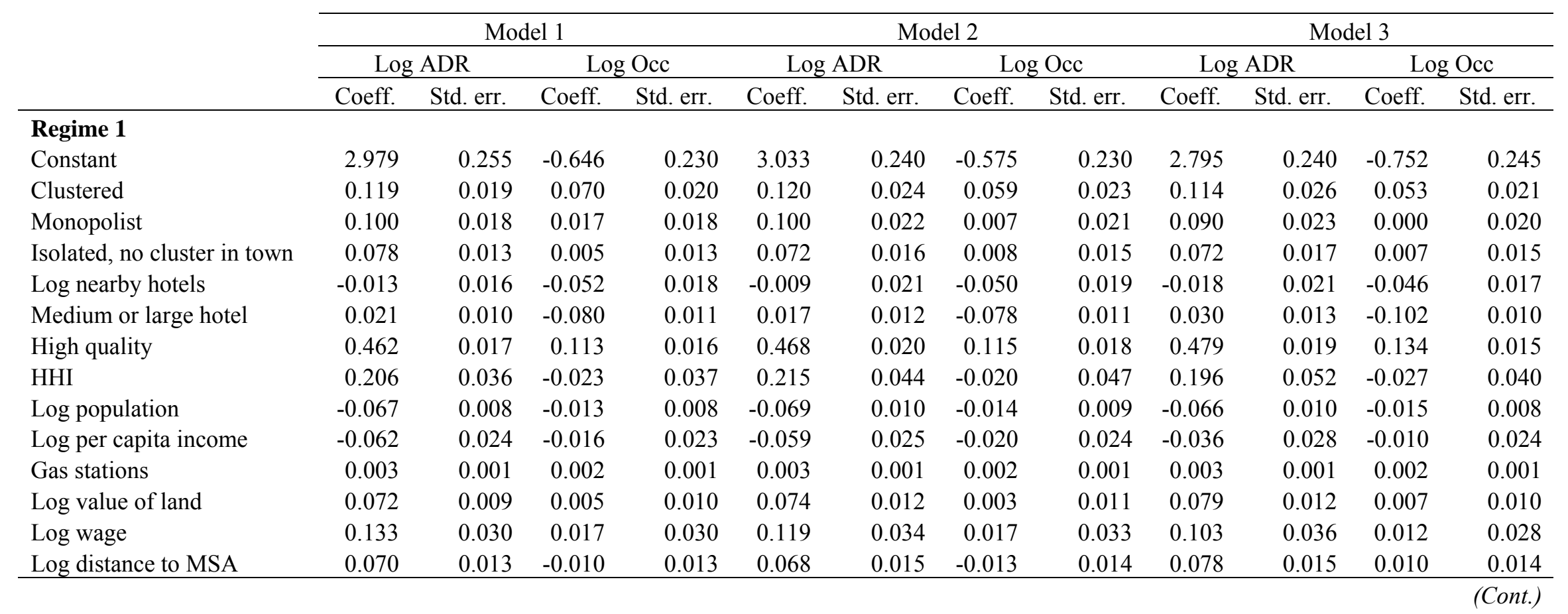




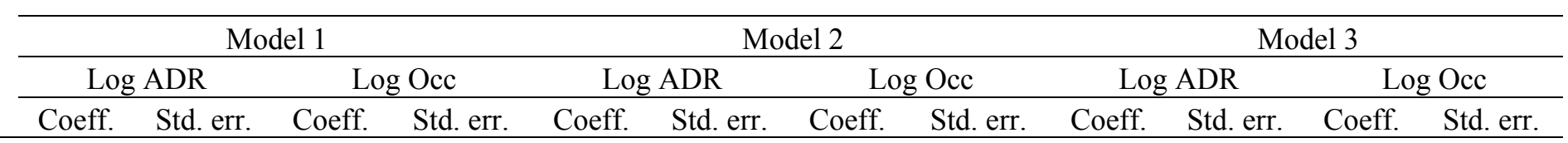

\begin{tabular}{|c|c|c|c|c|c|c|c|c|c|c|c|c|}
\hline \multicolumn{13}{|l|}{ Regime 2} \\
\hline Constant & -0.196 & 0.978 & -1.698 & 0.898 & -0.183 & 1.140 & -1.845 & 1.354 & -0.453 & 1.042 & -1.294 & 1.066 \\
\hline Monopolist & -0.031 & 0.050 & 0.133 & 0.046 & 0.032 & 0.058 & 0.118 & 0.045 & 0.013 & 0.057 & 0.146 & 0.048 \\
\hline Log nearby hotels & 0.289 & 0.057 & 0.073 & 0.056 & 0.289 & 0.059 & 0.103 & 0.053 & 0.365 & 0.066 & 0.096 & 0.057 \\
\hline Medium or large hotel & -0.252 & 0.032 & -0.089 & 0.031 & -0.261 & 0.032 & -0.091 & 0.030 & -0.144 & 0.039 & -0.181 & 0.039 \\
\hline High quality & 0.080 & 0.039 & 0.073 & 0.041 & 0.074 & 0.043 & 0.059 & 0.040 & 0.034 & 0.042 & 0.022 & 0.041 \\
\hline Log per capita income & 0.480 & 0.097 & 0.273 & 0.099 & 0.465 & 0.105 & 0.306 & 0.131 & 0.605 & 0.102 & 0.236 & 0.108 \\
\hline Gas stations & -0.015 & 0.003 & -0.005 & 0.003 & -0.015 & 0.003 & -0.007 & 0.003 & -0.020 & 0.003 & -0.004 & 0.003 \\
\hline Log value of land & 0.182 & 0.031 & -0.023 & 0.029 & 0.195 & 0.033 & -0.020 & 0.030 & 0.206 & 0.031 & -0.032 & 0.030 \\
\hline Log wage & -0.225 & 0.077 & -0.240 & 0.070 & -0.197 & 0.079 & -0.270 & 0.070 & -0.302 & 0.078 & -0.210 & 0.073 \\
\hline Log distance to MSA & 0.003 & 0.049 & 0.013 & 0.043 & -0.017 & 0.047 & 0.015 & 0.041 & -0.093 & 0.051 & -0.039 & 0.045 \\
\hline
\end{tabular}




\begin{tabular}{|c|c|c|c|c|c|c|}
\hline & \multirow{2}{*}{\multicolumn{2}{|c|}{ Model 1}} & \multirow{2}{*}{\multicolumn{2}{|c|}{ Model 2}} & \multirow{2}{*}{\multicolumn{2}{|c|}{ Model 3}} \\
\hline & & & & & & \\
\hline & Coeff. & Std. err. & Coeff. & Std. err. & Coeff. & Std. err. \\
\hline \multicolumn{7}{|l|}{ Probability of Regime 1} \\
\hline Clustered & & & 0.594 & 0.100 & 0.751 & 0.199 \\
\hline Monopolist & & & 0.474 & 0.135 & 0.543 & 0.132 \\
\hline High season & & & & & -0.156 & 0.078 \\
\hline Medium or large hotel & & & & & 1.354 & 0.112 \\
\hline$\sigma_{\varepsilon}^{1}$ & 0.229 & 0.003 & 0.230 & 0.003 & 0.230 & 0.004 \\
\hline$\sigma_{u}{ }^{1}$ & 0.233 & 0.003 & 0.234 & 0.004 & 0.238 & 0.003 \\
\hline$\rho^{2}$ & 0.342 & 0.010 & 0.343 & 0.011 & 0.310 & 0.012 \\
\hline \# observations & & 9,148 & & 9,148 & & 9,148 \\
\hline Log likelihood & & $-5,483.5$ & & $-5,419.4$ & & $-5,299.3$ \\
\hline
\end{tabular}

Note: All models include major top-chain, regional and time-period dummies. The top chains are Best Western, Best Value, Comfort, Days, Econolodge,

Holiday, Motel 6, Super 8, and Ramada. A hotel is considered clustered if it has a nearby competitor in a radius of 0.2 miles. Variance of correlation

coefficient obtained using the delta method. 
Table 9: Switching regression model of price (ADR) and occupancy rate, alternative cluster definitions

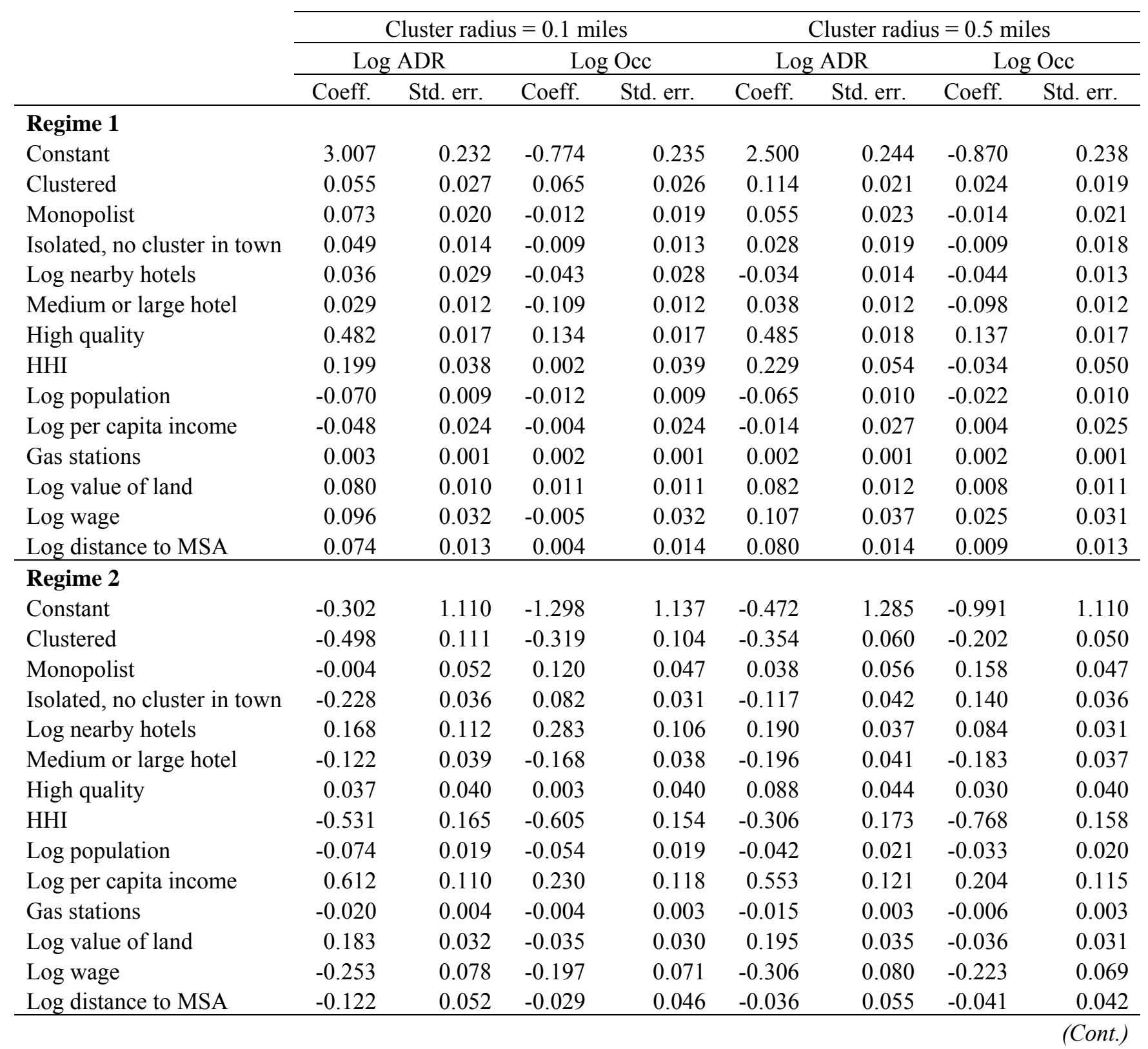




\begin{tabular}{lrrrr} 
& \multicolumn{3}{c}{ Cluster radius $=0.1$ miles } & \multicolumn{2}{c}{ Cluster radius $=0.5$ miles } \\
\cline { 2 - 5 } & \multicolumn{2}{c}{ Coeff. } & Std. err. & \multicolumn{2}{c}{ Coeff. } & Std. err. \\
\hline Probability of Regime 1 & & & & 0.034 \\
Constant & 0.409 & 0.075 & 1.530 & 0.157 \\
Clustered & 1.282 & 0.301 & 0.838 & 0.136 \\
Monopolist & 0.632 & 0.130 & -0.022 & 0.122 \\
Isolated, no cluster in town & -0.044 & 0.091 & -0.456 & 0.089 \\
Log nearby hotels & -0.692 & 0.324 & -0.150 & 0.072 \\
High season & -0.165 & 0.070 & 1.333 & 0.108 \\
Medium or large hotel & 1.367 & 0.110 & 0.232 & 0.003 \\
$\sigma_{\varepsilon}{ }^{1}$ & 0.232 & 0.003 & 0.237 & 0.003 \\
$\sigma_{u}{ }^{1}$ & 0.241 & 0.003 & 0.382 & 0.005 \\
$\rho^{1}$ & 0.373 & 0.006 & 0.451 & 0.010 \\
$\sigma_{\varepsilon}{ }^{2}$ & 0.431 & 0.010 & 0.441 & 0.007 \\
$\sigma_{u}{ }^{2}$ & 0.443 & 0.007 & 0.278 & 0.013 \\
$\rho^{2}$ & 0.314 & 0.011 & 9,148 \\
\hline Lobservations & & $-5,280.0$ & $-5,266.3$ \\
\hline Log likelihood
\end{tabular}

Note: All models include major top-chain, regional and time-period dummies. The top chains are Best Western, Best Value, Comfort, Days, Econolodge, Holiday, Motel 6, Super 8, and Ramada. Variance of correlation coefficient obtained using the delta method. 
Figure 1: Evolution of the lodging industry in Non MSA across Texas 1995-2005

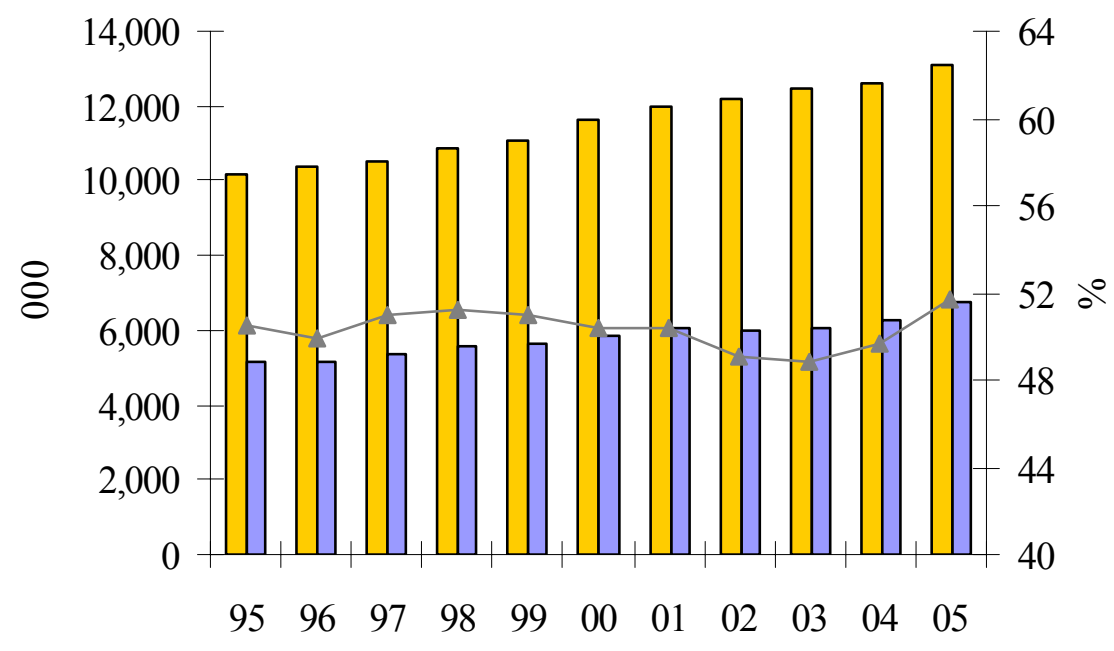

$\square$ room nights avail. $\square$ room nights sold $\longleftarrow$ occupancy

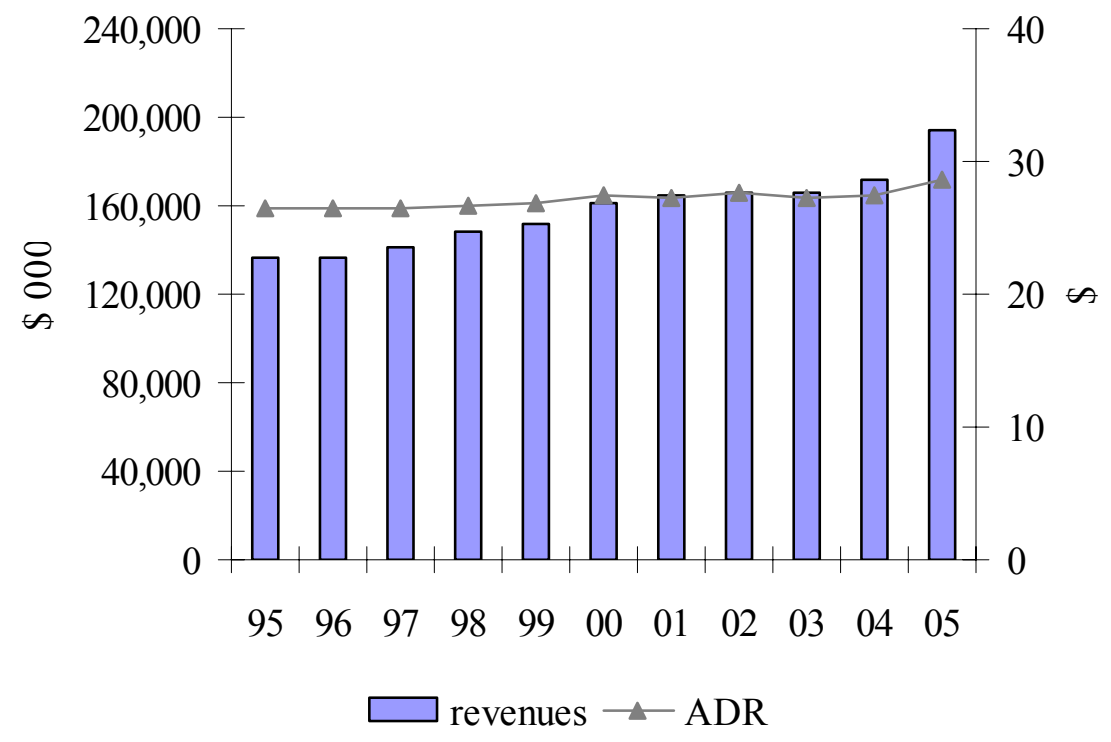

Note: Amounts expressed in 1982-84 CPI-adjusted dollars.

Source: www.travel.state.tx.us/asp/customreports.aspx 
Figure 2: ADR by relative location

\section{Mean}

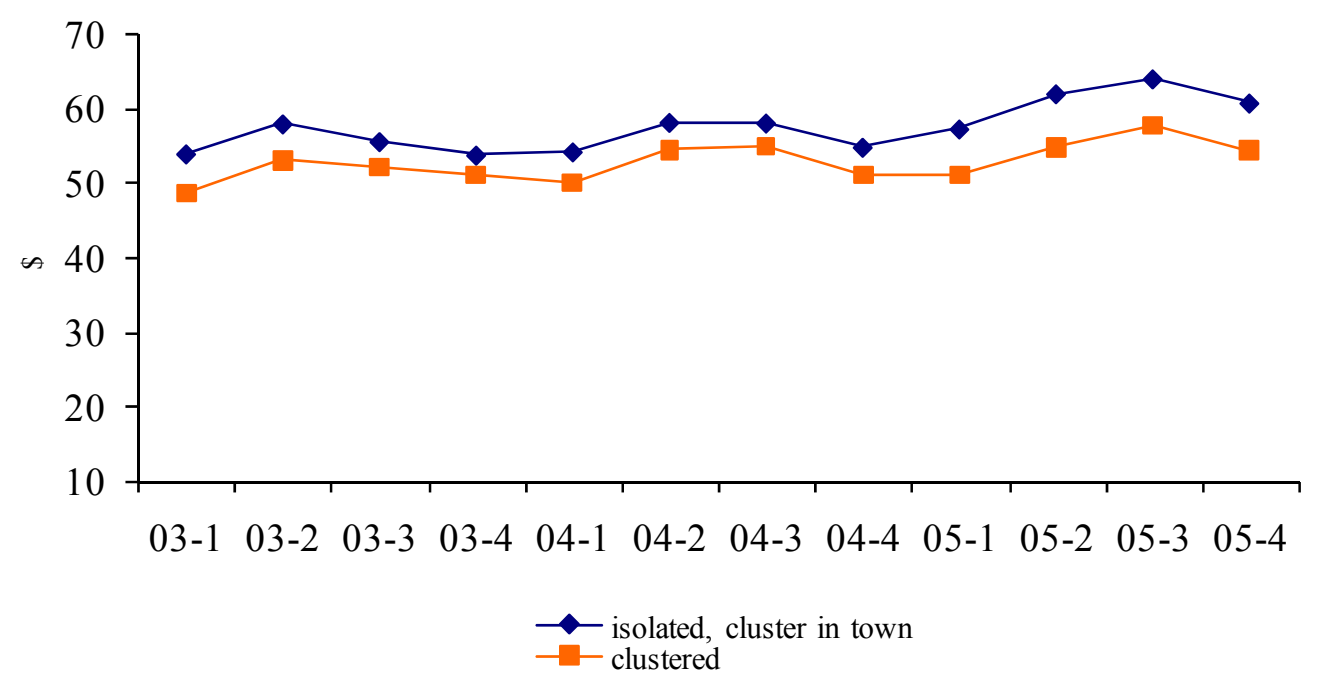

Standard deviation

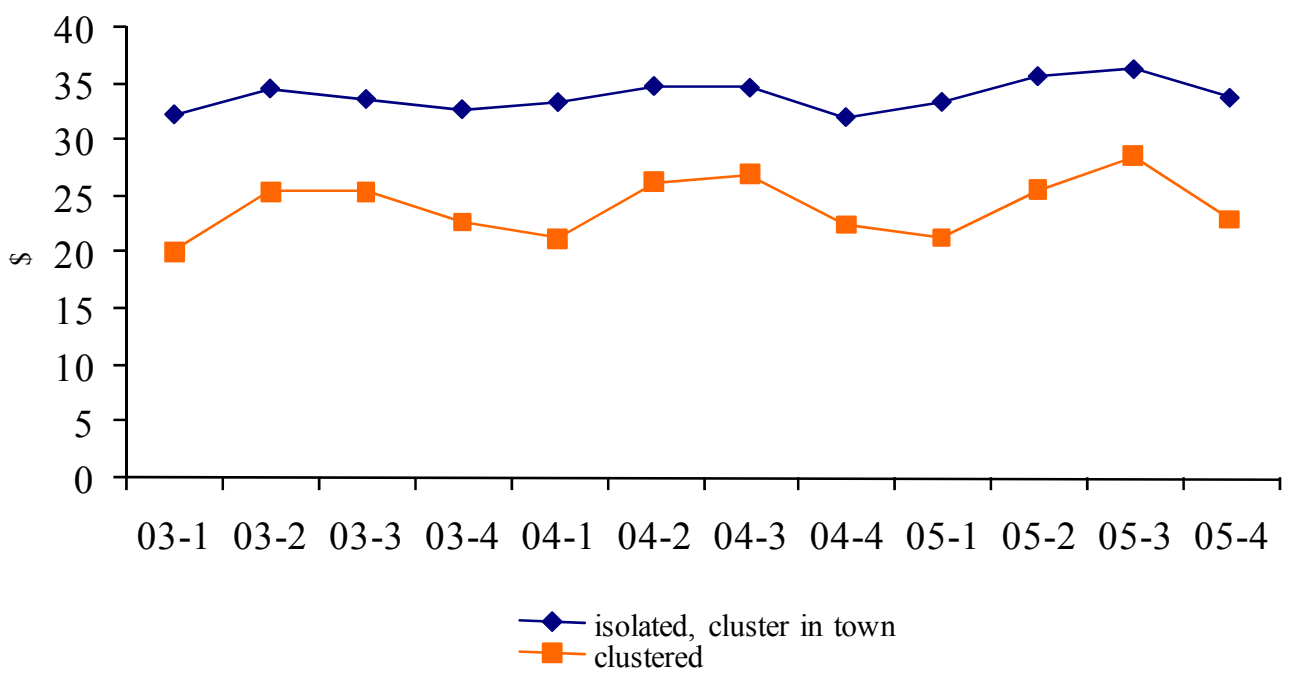

Note: A hotel is considered cluster if it has a competitor in a radius of 0.2 miles. 
Figure 3: Occupancy rate by relative location

Mean

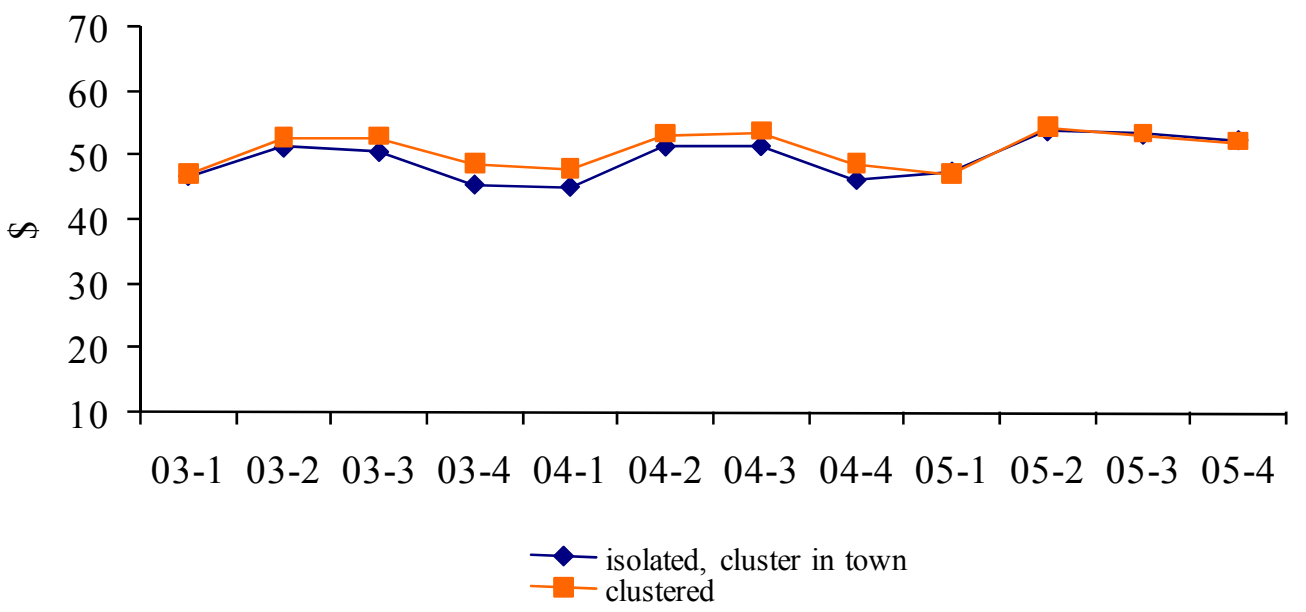

Standard deviation

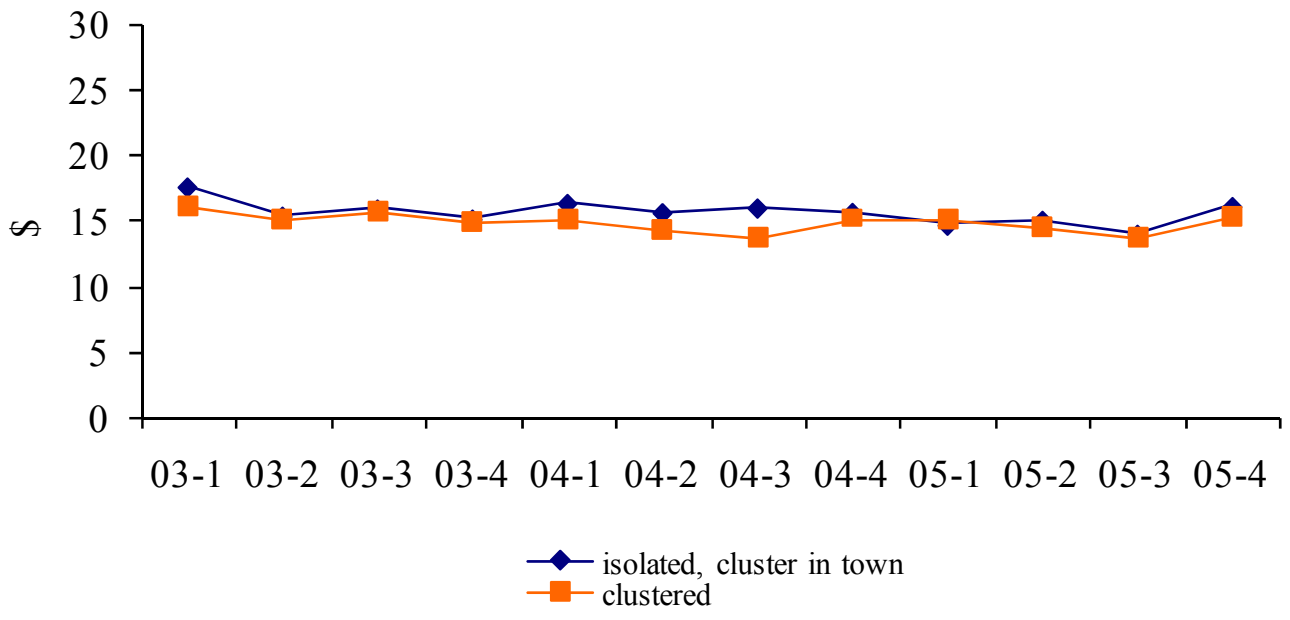

Note: A hotel is considered cluster if it has a competitor in a radius of 0.2 miles. 
Figure 4: Probability of colluding, conditional on being clustered

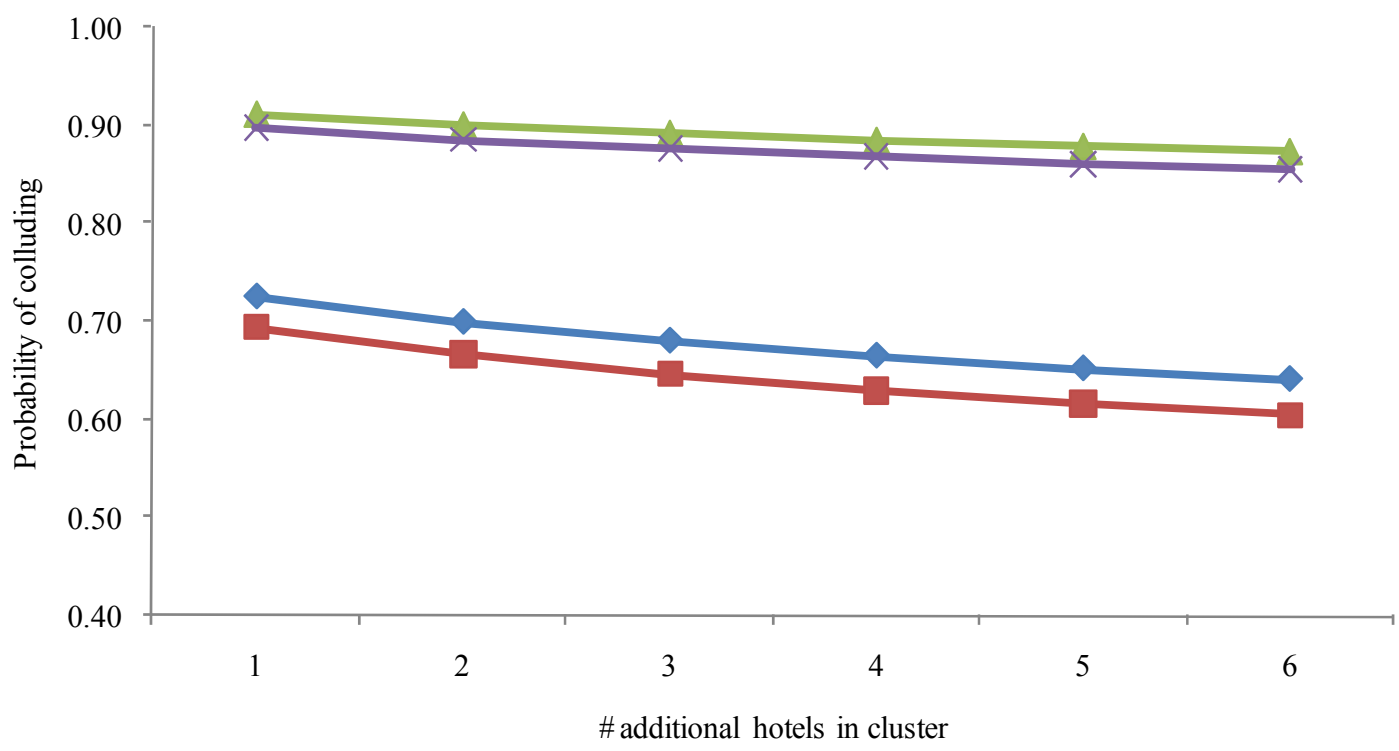

$\because$ Small hotel, low season $\quad \longrightarrow$ Small hotel, high season

$\longleftarrow$ Medium and large hotel, low season $\leftarrow$ Medium and large hotel, high season 
Figure 5: Probability of colluding, conditional on being clustered, by cluster definition

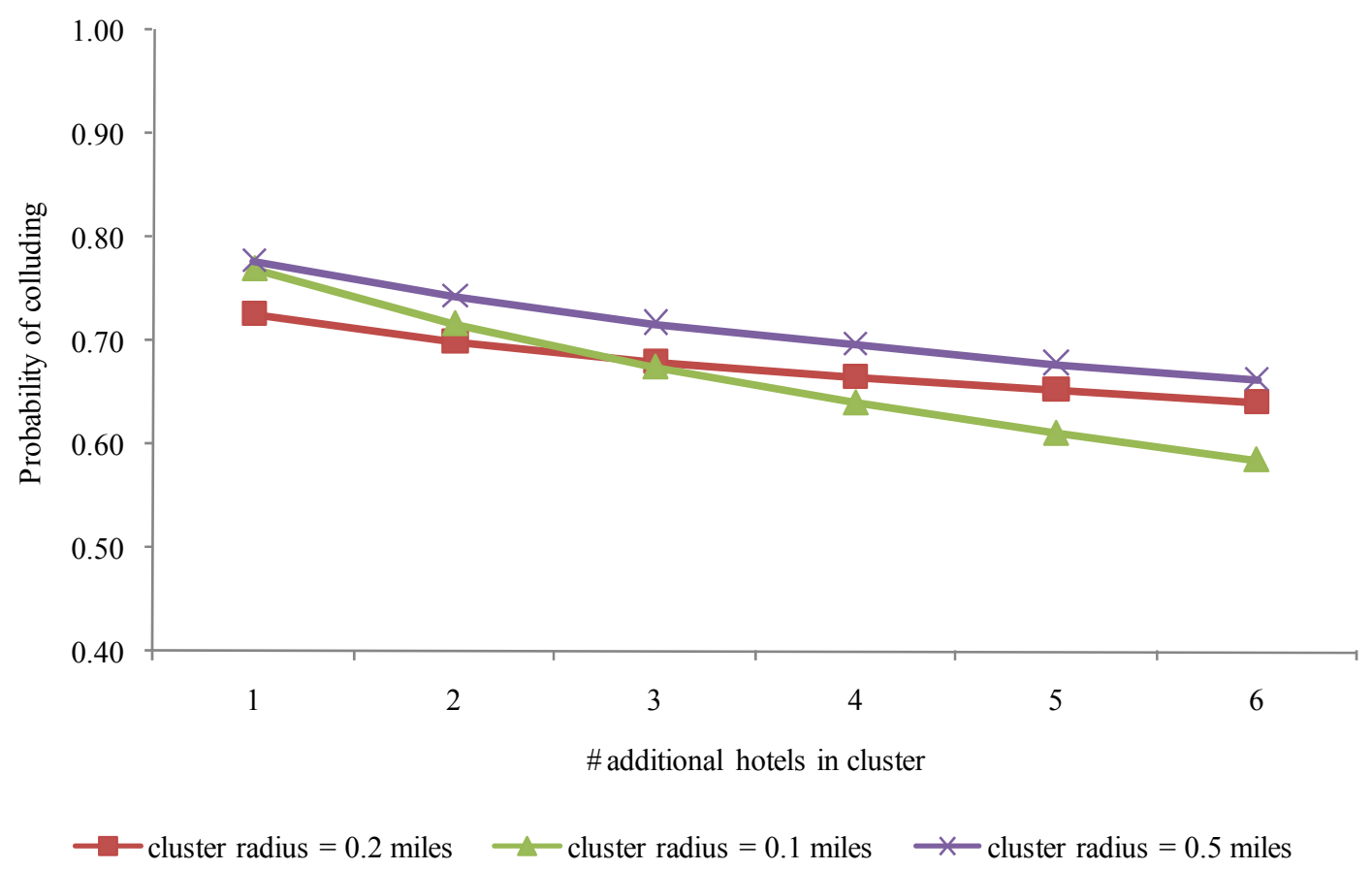

Note: Probabilities based on a small hotel and low season. 
Table A.1: Texas Hotel Performance Factbook - Description of variables

\begin{tabular}{|l|l|}
\hline Room counts & $\begin{array}{l}\text { Are checked annually in chain directories and the Texas American } \\
\text { Automobile Association (AAA) tour book. These properties account for } \\
\text { approximately } 80 \% \text { of the state revenues. Properties are also checked by } \\
\text { calling census and physical inspection by Source Strategies Inc. (SSI). } \\
\text { For independent properties too small to be listed, the room counts } \\
\text { reported to the Texas state government are used (unless they appear } \\
\text { unreasonable). As a result, "Chains" room counts are very close to } \\
\text { actual, while independent room counts could be slightly overstated. }\end{array}$ \\
\hline Average Daily Rates (ADR) & $\begin{array}{l}\text { Obtained from financial reports, appraisers, private SSI surveys, chain } \\
\text { and AAA directories, and another reliable industry database. }\end{array}$ \\
\hline Occupancy rate & $\begin{array}{l}\text { Is calculated from room nights sold and room nights available. All } \\
\text { occupancy figures represent fully-weighted averages. Room nights sold } \\
\text { are obtained by dividing gross room revenues reported to the State of } \\
\text { Texas Comptroller by ADR. Room nights available are calculated from } \\
\text { room counts times the number of days in the period. }\end{array}$ \\
\hline "Chains" & $\begin{array}{l}\text { Are defined as one of the "Top 50+" brands determined and tracked by } \\
\text { SSI. These brands may vary across time. Our sample includes, among } \\
\text { others, Americas Best Value, Best Western, Budget Host, Comfort, } \\
\text { Days, Econo Lodge, Hampton, Holiday, La Quinta, Motel 6, Ramada, } \\
\text { and Super 8. }\end{array}$ \\
\hline
\end{tabular}

Note: According to SSI, on an overall basis the changes in ADR reported are within a few tenths of onepercent of Smith Travel's "Lodging Outlook". Smith Travel Research (STR) is a private research firm that gets full financial reports of hotel/motel properties, accounting for $80 \%$ of the market, but it only publishes aggregate results. 


\section{Table A.2: AAA Diamond rating}

\begin{tabular}{|l|l|}
\hline One Diamond & $\begin{array}{l}\text { These establishments typically appeal to the budget-minded traveler. } \\
\text { They provide essential, no-frills accommodations. They meet the basic } \\
\text { requirements pertaining to comfort, cleanliness, and hospitality. }\end{array}$ \\
\hline Two Diamond & $\begin{array}{l}\text { These establishments appeal to the traveler seeking more than the basic } \\
\text { accommodations. There are modest enhancements to the overall } \\
\text { physical attributes, design elements, and amenities of the facility } \\
\text { typically at a moderate price. }\end{array}$ \\
\hline Three Diamond & $\begin{array}{l}\text { These establishments appeal to the traveler with comprehensive needs. } \\
\text { Properties are multifaceted with a distinguished style, including } \\
\text { marked upgrades in the quality of physical attributes, amenities, } \\
\text { and level of comfort provided. }\end{array}$ \\
\hline Four Diamond & $\begin{array}{l}\text { These establishments are upscale in all areas. Accommodations are } \\
\text { progressively more refined and stylish. The physical attributes reflect } \\
\text { an obvious enhanced level of quality throughout. The fundamental } \\
\text { hallmarks at this level include an extensive array of amenities combined } \\
\text { with a high degree of hospitality, service, and attention to detail. }\end{array}$ \\
\hline
\end{tabular}

Source: www.aaa-texas.com. 
Table A.3: Sources of information consulted to construct market controls

\begin{tabular}{|l|l|}
\hline \multicolumn{1}{|c|}{ Source } & \multicolumn{1}{|c|}{ Variable } \\
\hline $\begin{array}{l}\text { Texas State Data Center and Office of } \\
\text { the State Demographer } \\
\text { Texas Population Estimates Program } \\
\text { http://txsdc.utsa.edu/tpepp/txpopest.php }\end{array}$ & $\begin{array}{l}\text { Population } \\
\text { Annual population at the county level. }\end{array}$ \\
\hline $\begin{array}{l}\text { Bureau of Economic Analysis } \\
\text { http://bea.gov/bea/regional/reis }\end{array}$ & $\begin{array}{l}\text { Per capita income } \\
\text { Annual per capita personal income at the } \\
\text { county level. }\end{array}$ \\
\hline $\begin{array}{l}\text { Google Maps } \\
\text { www.google.com }\end{array}$ & $\begin{array}{l}\text { Gas stations } \\
\text { Number of gas stations at each location. }\end{array}$ \\
\hline $\begin{array}{l}\text { Real State Center at Texas A\&M University } \\
\text { www.recenter.tamu.edu/data/agp }\end{array}$ & $\begin{array}{l}\text { Value of land } \\
\text { Median per-acre value of rural land } \\
\text { per year at the land market area. }\end{array}$ \\
\hline $\begin{array}{l}\text { Bureau of Labor Statistics } \\
\text { www.bls.gov/data/home.htm }\end{array}$ & $\begin{array}{l}\text { Wage } \\
\text { Average weekly wage on leisure and } \\
\text { hospitality per quarter at the county level. }\end{array}$ \\
\hline $\begin{array}{l}\text { Mexas Tourism Travel Industry website } \\
\text { Economic Impact of Travel 2005 } \\
\text { www.travel.state.tx.us/EconomicImpact.aspx }\end{array}$ & $\begin{array}{l}\text { Distance to MSA } \\
\text { Mileage between location and nearest MSA. }\end{array}$ \\
\hline $\begin{array}{l}\text { Texas Comptroller of Public Accounts } \\
\text { www.window.state.tx.us/comptrol/texastra.html }\end{array}$ & Service Regions. \\
\hline
\end{tabular}


Table A.4: Locations included in the study by region

\begin{tabular}{|c|c|}
\hline Regions & Locations \\
\hline $\begin{array}{l}\text { Central Texas } \\
\text { (42 locations) }\end{array}$ & $\begin{array}{l}\text { Blanco, Brenham, Buchanan Dam, Buffalo, Burnet, Cameron, Centerville, } \\
\text { Chappell Hill, Clifton, Fairfield, Flatonia, Giddings, Goldthwaite, Granite } \\
\text { Shoals, Groesbeck, Hamilton, Hico, Hillsboro, Hilltop Lakes, Horseshoe Bay, } \\
\text { Iredell, Jewett, Johnson City, Kingsland, Kopperl, La Grange, Laguna Park, } \\
\text { Lake Whitney, Llano, Madisonville, Marble Falls, Marlin, Meridian, Mexia, } \\
\text { Navasota, Rockdale, Round Top, San Saba, Schulenburg, Streetman, } \\
\text { Tow, Whitney. }\end{array}$ \\
\hline $\begin{array}{l}\text { Gulf Coast } \\
(12)\end{array}$ & $\begin{array}{l}\text { Bay City, Columbus, Eagle Lake, El Campo, Frelsburg, Huntsville, Matagorda, } \\
\text { Midfield, Palacios, Pierce, Weimar, Wharton. }\end{array}$ \\
\hline $\begin{array}{l}\text { High Plains } \\
(28)\end{array}$ & $\begin{array}{l}\text { Borger, Brownfield, Canadian, Childress, Clarendon, Dalhart, Denver City, } \\
\text { Dimmit, Dumas, Floydada, Friona, Hereford, Levelland, Littlefield, Memphis, } \\
\text { Muleshoe, Pampa, Perryton, Plainview, Post, Shamrock, Spearman, Stratford, } \\
\text { Tulia, Vega, Wellington, Wheeler, Wildorado. }\end{array}$ \\
\hline $\begin{array}{l}\text { Metroplex } \\
(12)\end{array}$ & $\begin{array}{l}\text { Bluff Dale, Bonham, Corsicana, Dublin, Gainesville, Glen Rose, Graford, } \\
\text { Granbury, Mineral Wells, Mingus, Stephenville, Strawn. }\end{array}$ \\
\hline $\begin{array}{l}\text { Northwest Texas } \\
(28)\end{array}$ & $\begin{array}{l}\text { Albany, Aspermont, Ballinger, Bowie, Breckenridge, Brownwood, Cisco, } \\
\text { Coleman, Colorado City, Comanche, De Leon, Early, Eastland, Graham, } \\
\text { Haskell, Jacksboro, Knox City, Nocona, Olney, Quanah, Ranger, Santa Anna, } \\
\text { Seymour, Snyder, Stamford, Sweetwater, Valera, Vernon. }\end{array}$ \\
\hline $\begin{array}{l}\text { South Texas } \\
(48)\end{array}$ & $\begin{array}{l}\text { Alice, Beeville, Brackettville, Camp Wood, Carrizo Springs, Concan, Cotulla, } \\
\text { Crystal City, Cuero, Del Rio, Dilley, Eagle Pass, Edna, Escobares, Falfurrias, } \\
\text { Fredericksburg, Freer, George West, Gonzales, Hallettsville, Hebbronville, } \\
\text { Hunt, Ingram, Kenedy, Kerrville, Kingsville, Leakey, Mountain Home, Orange } \\
\text { Grove, Pearsall, Port Mansfield, Premont, Raymondville, Refugio, Rio Frio, } \\
\text { Rio Grande City, Riviera, Rocksprings, Roma, Sarita, Shiner, Smiley, Stonewall, } \\
\text { Three Rivers, Utopia, Uvalde, Yoakum, Zapata. }\end{array}$ \\
\hline $\begin{array}{l}\text { Southeast Texas } \\
(20)\end{array}$ & $\begin{array}{l}\text { Broaddus, Brookeland, Center, Crockett, Diboll, Etoile, Hemphill, Jasper, } \\
\text { Kirbyville, Livingston, Lufkin, Milam, Nacogdoches, Newton, Onalaska, } \\
\text { Sam Rayburn, San Augustine, Seven Oaks, Trinity, Woodville. }\end{array}$ \\
\hline $\begin{array}{l}\text { Upper East Texas } \\
(28)\end{array}$ & $\begin{array}{l}\text { Alba, Athens, Atlanta, Canton, Carthage, Clarksville, Emory, Frankston, } \\
\text { Grand Saline, Gun Barrel City, Hawkins, Hughes Springs, Jacksonville, } \\
\text { Jefferson, Malakoff, Marshall, Mineola, Mount Pleasant, Mount Vernon, } \\
\text { Palestine, Paris, Queen City, Quitman, Rusk, Scroggins, Sulphur Springs, } \\
\text { Van, Wills Point. }\end{array}$ \\
\hline $\begin{array}{l}\text { Upper Rio Grande } \\
\text { (11) }\end{array}$ & $\begin{array}{l}\text { Alpine, Big Bend National Park, Fort Davis, Fort Hancock, Lajitas, Marathon, } \\
\text { Marfa, Presidio, Shafter, Terlingua, Van Horn. }\end{array}$ \\
\hline $\begin{array}{l}\text { West Texas } \\
(21)\end{array}$ & $\begin{array}{l}\text { Andrews, Big lake, Big Spring, Brady, Crane, Eden, Fort Stockton, Iraan, } \\
\text { Junction, Kermit, Lamesa, Mason, Menard, Monahans, Ozona, } \\
\text { Paint Rock, Pecos, Rankin, Sanderson, Seminole, Sonora. }\end{array}$ \\
\hline
\end{tabular}

Note: Regions based on Uniform State Service Regions.

Source: $\underline{\text { www.travel.state.tx.us/EconomicImpact.aspx. }}$ 